\title{
Stratosphere-troposphere exchange from the Lagrangian perspective: a case study and method sensitivities
}

\author{
M. S. Bourqui \\ McGill University, Montreal, Canada \\ Received: 30 April 2004 - Published in Atmos. Chem. Phys. Discuss.: 18 June 2004 \\ Revised: 1 June 2006 - Accepted: 2 June 2006 - Published: 5 July 2006
}

\begin{abstract}
An important part of extra-tropical stratosphereto-troposphere transport occurs in association with baroclinic wave breaking and cut-off decay at the tropopause. In the last decade many studies have attempted to estimate stratospheretroposphere exchange (STE) in such synoptic events with various methods, and more recently efforts have been made to inter-compare these methods. These inter-comparisons show large variations between estimates from different methods. This large uncertainty points to a need to thoroughly evaluate such methods, assess the realism of the resulting STE estimates and determine the sensitivities to intrinsic parameters of the methods.

The present study focuses on a trajectory-based Lagrangian method which has been applied in the past to climatological studies. This method is applied here to the quantification of STE in the context of a typical baroclinic wave breaking event. The analysis sheds light on (i) the complex three-dimensional temporal and spatial structures that are associated with the rapid inflow of stratospheric air into the troposphere, (ii) the variation of STE mass flux with the choice of the dynamical tropopause definition within 1.5 to $5 \mathrm{PVU}$, (iii) the sensitivity of the results to resolution, and in particular the minimum spatial resolution of $1^{\circ} \times 1^{\circ}$ required to reasonably capture STE fluxes in this wave breaking event, (iv) the effective removal of spurious exchange events using a threshold residence time larger than $8 \mathrm{~h}$.
\end{abstract}

\section{Introduction}

The exchange of mass between the stratosphere and the troposphere has important implications for climate and life conditions on the Earth's surface. Injection of ozone-rich stratospheric air into the troposphere is recognised to sig-

Correspondence to: M. S. Bourqui

(michel.bourqui@mcgill.ca) nificantly force the chemistry and subsequently the radiation (e.g. Roelofs and Lelieveld, 1997), and can enhance episodically the ozone concentration in the boundary layer (Wernli and Bourqui, 2002; Ladstätter-Weissenmayer et al., 2004). Transport of tropospheric air (with natural and anthropogenic emissions) into the stratosphere perturbs the lower stratospheric chemistry and can inject significant amounts of water vapour in the stratosphere (Dessler and Sherwood, 2004). Recent studies have also suggested that cross-tropopause mass flux may increase during the 21st Century as a result of climate change (Sudo et al., 2003; Collins et al., 2003). According to these studies, the long term enhancement of stratospheric sources of ozone would significantly modify the tropospheric ozone budget. For convenience, we use hereafter the abbreviations STT for stratosphere-to-troposphere transport, TST for troposphere-to-stratosphere transport, and STE for general stratosphere-troposphere exchange.

Due to its particular relevance, STE has received a lot of attention during the last two decades, and some key properties have been identified. On the one hand, STE can be seen to some extent as the lowest branch of the BrewerDobson circulation (Holton et al., 1995). The latter, understood here as the mean residual circulation resulting from the Transformed Eulerian Mean framework (Andrews et al., 1987), is mainly driven by planetary wave breaking within the middle stratosphere "surf zone" (McIntyre and Palmer, 1983; Haynes et al., 1991). On the other hand, tropospheric dynamics influence to a large extent the tropopause region and hence the flux across the tropopause. The vertical mass flux in the tropopause region associated with this circulation exhibits very different distributions whether it is calculated across $\mathrm{PV}^{1}$ iso-surfaces, isentropes or isobaric surfaces, due to the different vertical motion of these surfaces relative to the flow (Juckes, 2001). While the diabatic circulation is reflected in the cross-isentropic motion (Haynes et al., 1991),

\footnotetext{
${ }^{1} \mathrm{PV}$ denotes the Ertel's potential vorticity.
} 
the cross-tropopause flux is by definition a motion across isoPV surfaces if the dynamical tropopause is to be considered (Appenzeller et al., 1996b).

In the extra-tropics, injection of stratospheric air into the troposphere has been detected almost exclusively in regions of upper-level troughs and cut-off lows (e.g. Danielsen, 1980; Shapiro, 1980; Ancellet et al., 1991; Langford et al., 1996; Eisele et al., 1999). These structures are part of baroclinic wave life-cycles and are frequently associated with the production of folding and filamentation structures (e.g. Bush and Peltier, 1994; Bithell et al., 1999). The physical processes responsible for STT have been analysed in numerous studies and a variety of mechanisms has been identified. Their relative importance varies significantly from case to case. The presence of clouds in the upper-troposphere (often induced on the warm, downstream side of an upper-level trough) and the associated latent heat release leads systematically to a significant inflow of stratospheric air into the troposphere (e.g. Lamarque and Hess, 1994; Wirth, 1995a). Turbulence in the region of the jet stream in the absence of clouds (clear air turbulence) has been identified (Shapiro, 1976) and its significance for stratosphere-troposphere exchange demonstrated (Shapiro, 1980). The formation of small-scale filaments or folds and their irreversible mixing is also recognised to account for a significant part of the overall exchanged mass (e.g. Price and Vaughan, 1993; Hartjenstein, 2000). Physical processes involved in TST in the extra-tropics have also been studied. Radiative effects in anticyclones, in particular those related to the water vapour profile, can induce upward transport (e.g. Hoskins et al., 1985; Zierl and Wirth, 1997). Additionally, intense convective complexes which reach the tropopause are likely to inject tropospheric air into the stratosphere by convective transport (Poulida et al., 1996; Stenchikov et al., 1996; Mullendore et al., 2005) or via breaking of gravity waves generated above cumulus clouds (Wang, 2003).

Methods estimating STE at synoptic scales must be able to resolve the motions of the flow and of the tropopause at the scales on which the involved physical processes are acting, otherwise they may misrepresent the differential motion of the flow and the tropopause. However, if such methods are to produce estimates on the global scale, they must in addition be applicable to global meteorological data with synopticscale resolution such as operational (re-)analysis data. In past studies, such quantifications have been carried out using merely four types of methods:

(1) The methods based upon Eulerian formulations of the cross-tropopause flux and estimating individual terms of the formulation (e.g. Wei, 1987; Wirth, 1995b; Wirth and Egger, 1999).

(2) The methods explicitely estimating the non-advective part of the motion of the tropopause (Lamarque and Hess, 1994; Wirth and Egger, 1999).
(3) The methods using a trajectory-based Lagrangian representation of the flow (e.g. Wernli and Davies, 1997; Stohl, 2001; Wernli and Bourqui, 2002).

(4) The methods using transport schemes with physics parameterizations and estimating the cross-tropopause transport of a tracer (e.g. Gray, 2003; Roelofs et al., 1997).

The study of Wirth and Egger (1999) inter-compared in the context of a case-study several methods based on Eulerian formulations and a method of type (2) employing trajectories to advect passively the tropopause. They suggested that methods of type (1) produce reasonable estimates when formulated with a PV - vertical coordinate and produce noisy estimates in all other cases. Note that the PV - vertical coordinate formulation of the mass flux requires a direct estimate of the material derivative of PV. This quantity was available as model output in the study of Wirth and Egger (1999), but can not in general be derived from meteorological fields with a reasonable confidence. They also suggested that type (2) methods produce reliable estimates. In another intercomparison study, Kowol-Santen et al. (2000) estimated STE from a mesoscale model output with a type (1) methodology formulated in isentropic vertical coordinates and a type (3) method. Although the net mass flux estimated from the two methods was in agreement, the separated STT and TST mass fluxes were found to be noisier in the type (1) method.

The study of Gray (2003) used a mesoscale model to derive the fluxes of stratospheric air through the tropopause using a passive tracer (type (4) method). They showed a substantial sensitivity of the estimates to the horizontal and vertical resolutions, as well as an equally large sensitivity to the hyperdiffusion coefficient. Net STT estimates converged rapidly when resolution was increased from $2^{\circ}$ to $1^{\circ}$, $0.5^{\circ}$ and $0.11^{\circ}$, and with adequatly decreased hyperdiffusion. Resolutions of $1^{\circ}$ and $0.5^{\circ}$ gave estimates reasonably close to those at $0.11^{\circ}$ resolution. Their results suggested also that a large part of the cross-tropopause mass flux comes from the model's explicit advection, with still a maximum of $38 \%$ attributed to parameterized convection and less than this to parameterized turbulent mixing. The fraction due to convective transport was however sensitive to the hyperdiffusion, and may vary from one model to another. Roelofs et al. (1997) inter-compared STE estimates from tropospheric chemistryclimate models nudged toward analysis data and chemistrytransport models driven by analysis data. The models were operating at resolutions of $1.8^{\circ}$ and lower. The simulated ozone distributions for the selected tropopause folding event showed considerable differences between the models, suggesting significant differences in cross-tropopause fluxes.

Wernli and Bourqui (2002) introduced a Lagrangian method using a threshold residence time. This method is based on a representation of the flow by three-dimensional trajectories, started from a dense three-dimensional grid and computed using wind fields from the European Centre for 
Medium-Range Weather Forecasts (ECMWF) operational analyses. Exchange events are then selected from the trajectories that reside within the troposphere and the stratosphere before and after having crossed the tropopause for a period longer than a given threshold residence time $\tau^{*}$. They produced a one-year climatology of exchange in the extra-tropical northern hemisphere with a detailed geographical distribution which was in quantitative agreement with independent results from methods cast in the zonal mean framework. The extension of the climatology to fifteen years mainly confirmed these results (Sprenger and Wernli, 2003).

Within the EU project STACCATO (Stohl et al., 2003), this trajectory-based Lagrangian method took part in a method inter-comparison and verification exercise based upon selected case studies of STE in the European sector (Meloen et al., 2003; Cristofanelli et al., 2003). The intercomparison included in particular Lagrangian transport models with physics parameterizations, chemical transport models and general circulation models (type (4)). It was shown that purely trajectory-based approaches yield lower bound estimates of STE because they capture the large-scale transport but no turbulent nor diffusive processes. Particle dispersion models with parameterized turbulence led to slightly larger cross-tropopause mass fluxes, while estimates from relatively coarse scale global models were distinctively larger and were shown to suffer from numerical diffusion. Indeed, for the cases under consideration, based upon a limited observational data set available for validation, and in sight of the uncertainties implied by parameterizations on transport, the trajectory-based Lagrangian approach accurately identified regions subject to stratosphere-to-troposphere transport and provided quantitative estimates that can be regarded as realistic lower bounds.

A key element introduced in the study of Wernli and Bourqui (2002) was the threshold residence time, used to select the significant exchange events. They suggested that anticipated errors in the mass flux due to derivation of PV and trajectory calculation were likely to introduce spurious exchange events mostly associated with small residence times. Based upon this assumption and the fact that small residence times imply potentially weak chemical action, they suggested filtering out the small residence time events by employing a threshold residence time. This distinction between short and long residence time events was also found to be crucial in the study of James et al. (2003) where more than $90 \%$ of the cross-tropopause flow was found to return witin $6 \mathrm{~h}$ to its original layer. A theoretical study has been carried out recently by Hall and Holzer (2003) on the advectivediffusive mass flux through a surface and associated residence time distribution. The study concluded that in the small residence time limit, in the absence of scale limitations, the separated fluxes become infinite. Equivalently, the gross fluxes are completely dominated by fluid elements residing infinitesimally. In presence of scale limitations due to finite data resolution, the gross fluxes are dominated by the smallest scales resolved. Consequently, estimates of separated STT and TST fluxes will intrinsically depend on the threshold residence time that is either explicitely applied or implicitely present.

The motivation of the present study is to gain a deeper understanding of the methodology introduced in Wernli and Bourqui (2002), and along with this a deeper understanding of basic cross-tropopause transport properties, in the context of a case study with special emphases on the residence time, the data resolution and the PV-tropopause definition. In addition, the potential offered by the method for detailed physical analyses of the processes involved is illustrated.

The structure of the paper is as follows. In Sect. 2 we describe the data set and the Lagrangian method. Then, in Sect. 3 the baroclinic wave event under consideration is briefly described, results of STE estimates are presented and further details are shown using three-dimensional views. In Sect. 4 is discussed the sensitivity of the method to data resolution, threshold residence time and the PV-tropopause definition. And finally, conclusions are drawn in Sect. 5.

\section{Data and method}

The cross-tropopause flux calculation is based on hourly outputs of the limited-area Europa Model (EM) of the German Weather Service (Majewski, 1991). The resolution in the model is $0.5^{\circ} \times 0.5^{\circ}$ in the horizontal and 40 levels in the ver$\mathrm{tical}^{2}$. The hindcast simulation is performed for a duration of $162 \mathrm{~h}$ from 1 September 1997 00:00 UTC to 7 September 1997 18:00 UTC, and uses the six-hourly ECMWF analysis fields (T213L31) as initial and boundary conditions. The simulation domain is drawn in Fig. 1 by the bold line. The simulation results compare reasonably well with the verifying ECMWF analyses (not shown), and reproduce correctly the different phases of the synoptic and mesoscale development both in amplitude and location. A slightly smaller domain than the simulation domain is used for the quantification of exchange (see Fig. 1, filled domain). To enable the computation of trajectories outside the simulation domain ECMWF analysis data are used to extend the data domain to the whole northern hemisphere.

The method for quantifying the stratosphere-troposphere exchange flux is an adaptation of the trajectory-based method introduced by Wernli and Bourqui (2002) allowing for a higher temporal and spatial resolution of the data within a limited area (Bourqui, 2001). We summarise here the main features of the method and the parameters that were used to achieve the results presented in Sect. 3. The sensitivity of the method to the main parameters is discussed in Sect. 4.

The definition of an exchange event is based on the condition that the trajectory resides for a time period longer than a given threshold residence time $\tau^{*}$ in either sides of the

\footnotetext{
${ }^{2}$ Levels every $20 \mathrm{hPa}$ in the tropopause region between 150 and $510 \mathrm{hPa}$, and every $30 \mathrm{hPa}$ elsewhere with the top level at $30 \mathrm{hPa}$.
} 


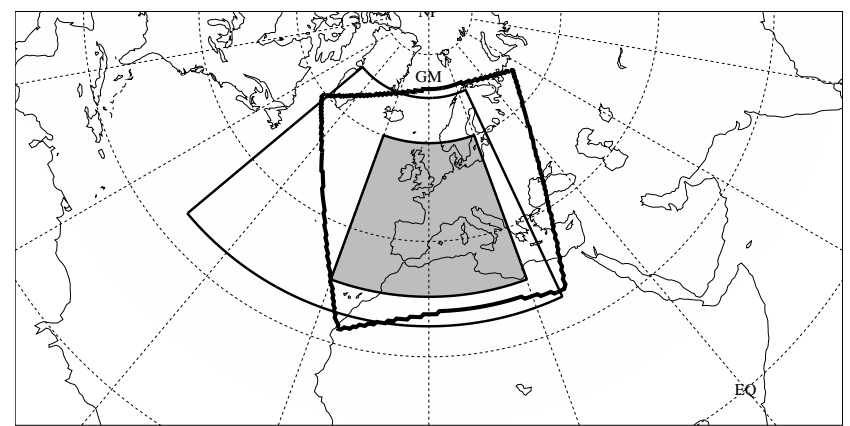

Fig. 1. Domains used in the methodology. Filled: diagnosis domain for cross-tropopause transport. Bold line: EM simulation domain. Solid line: Trajectory starting grid domain.

tropopause before and after having crossed the tropopause (see schematic illustration in Fig. 2). The trajectories are computed with the three-dimensional LAGRangian ANalysis TOol LAGRANTO (Wernli and Davies, 1997) based on Petterssen's kinematic method (Petterssen, 1956). In this study, the $2 \mathrm{PVU}^{3}$ surface is used as tropopause definition because it mimics reasonably well the thermal tropopause in the extratropics (Holton et al., 1995) and is a well-defined, continuous surface with conservative properties.

The set of exchange trajectories is obtained by a threestep computation scheme. First, the time-dependent flow is discretisized spatially and temporally into a set of trajectories. The trajectories are started every $12 \mathrm{~h}$ for a duration of $12 \mathrm{~h}$ from a starting grid extending vertically from 600 to $50 \mathrm{hPa}$ and horizontally as shown in Fig. 1. The starting points are separated from each other horizontally by $0.5^{\circ}$ and vertically by $5 \mathrm{hPa}$, so that each trajectory represents an air mass $\Delta m=g^{-1} \cdot \Delta x \cdot \Delta y \cdot \Delta p \approx 157 \times 10^{9} \mathrm{~kg}$. Second, the $12 \mathrm{~h}$ trajectories which cross the $2 \mathrm{PVU}$ surface are extended for 5 days both backwards and forwards. Third, the selection is performed on every extended trajectory according to the conceptual model illustrated in Fig. 2. Each trajectory must reside within the troposphere and the stratosphere for periods longer than the given threshold residence time $\tau^{*}$. The two residence time periods, within the troposphere and within the stratosphere, are separated by a transition time smaller than a given $T_{\max }^{\text {trans }}$. This maximum transition time allows the trajectories to oscillate around the tropopause while crossing it. The parameters used here are $12 \mathrm{~h}$ for the threshold residence time $\tau^{*}$ and $6 \mathrm{~h}$ for the maximum transition time $T_{\max }^{\text {trans }}$. This choice of residence time will be justified in Sect. 4.2, while the choice of transition time follows from the constraint that it must be small in comparison to the residence time while still allowing for some oscillation when crossing the tropopause (Bourqui, 2001).

\footnotetext{
${ }^{3} \mathrm{PVU}$ denotes the Ertel's potential vorticity unit: $1 \mathrm{PVU}=10^{-6} \mathrm{~m}^{2} \mathrm{~s}^{-1} \mathrm{~K} \mathrm{~kg}^{-1}$.
}

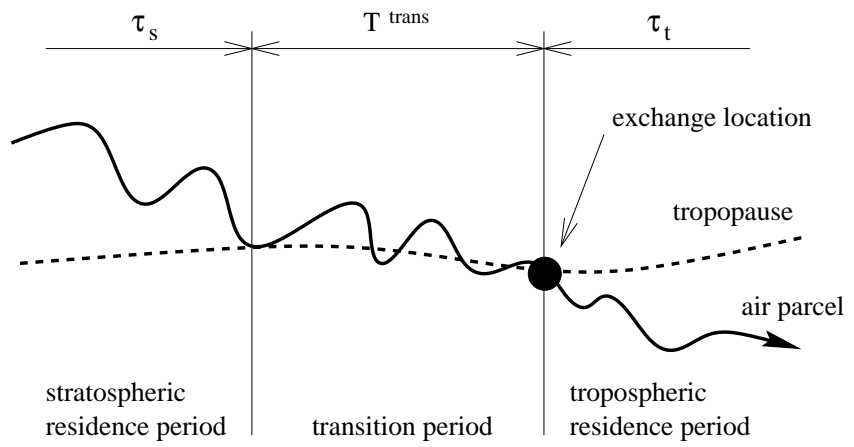

Fig. 2. Conceptual Lagrangian model of an exchange event. A trajectory has experienced a significant exchange if $\tau_{s}>\tau^{*}, \tau_{t}>\tau^{*}$, and $T^{\text {trans }}<T_{\max }^{\text {trans }}$, for given $\tau^{*}$ and $T_{\max }^{\operatorname{trans}}$

Finally, the exchange mass flux is given by the sum of the mass transported by the trajectories which experience an exchange within a $1^{\circ} \times 1^{\circ}$ grid-square during each period of $12 \mathrm{~h}$.

In essence, this method is identical to the one used by Wernli and Bourqui (2002), but is applied to a resolution of $0.5^{\circ} \times 0.5^{\circ} \times 1 \mathrm{~h}$ instead of $1^{\circ} \times 1^{\circ} \times 6 \mathrm{~h}$. The transition period of $6 \mathrm{~h}$ is introduced here only because of the increased temporal data resolution.

\section{Results}

\subsection{Synoptic evolution of the tropopause}

The synoptic situation corresponds to the late stage of a typical baroclinic wave development similar to the anticyclonicshear case described by Davies et al. (1991) and Thorncroft et al. (1993), and includes the break-up of a stratospheric streamer ${ }^{4}$ and the decay of the resulting cut-off. Figure 3 shows a $12 \mathrm{~h}$ time sequence of potential temperature at the tropopause and cloud water content at $310 \mathrm{~K}$ (red contours and shading). Note that the interpolation of potential temperature on the $2 \mathrm{PVU}$ surface provided here reflects faithfully the structure of the tropopause and allows a dynamical interpretation similar to that of isentropic potential vorticity charts (Hoskins et al., 1985; Hoskins, 1991). In principle, such interpolation may lead to a misrepresentation of situations with multiple tropopauses in the vertical. In our particular case however, although the tropopause is close to vertical in some regions, there are no significant multiple tropopauses in the sector of interest.

At the beginning of the period of interest, an elongated, north-south oriented streamer is arriving over Western Spain and the United Kingdom, as shown in Fig. 3a for 1 September 06:00 UTC. Over the following twelve hours,

\footnotetext{
${ }^{4}$ Following Appenzeller et al. (1996a), a streamer is a synopticscale equatorward advection of high potential vorticity on an isentropic PV map.
} 

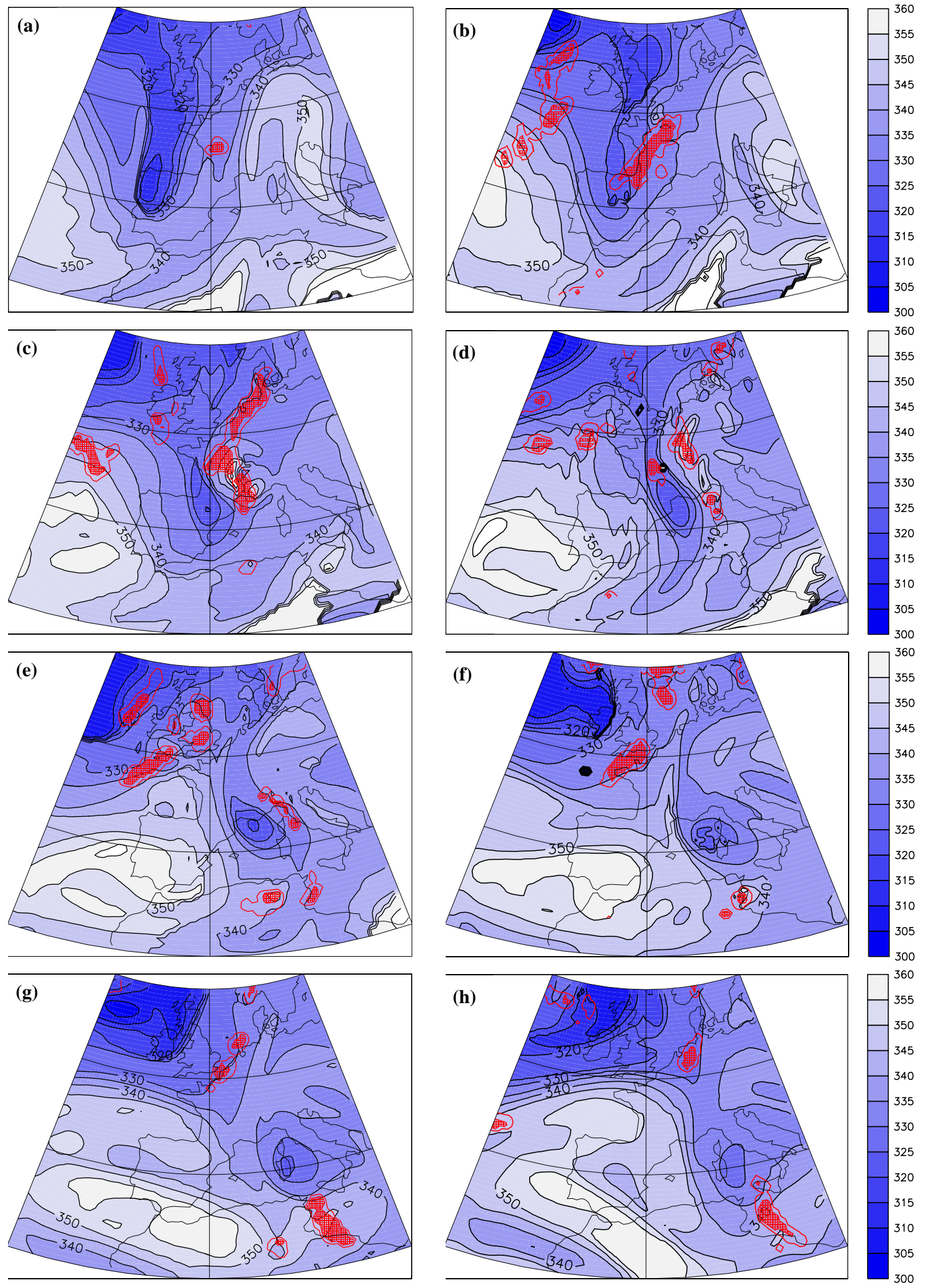

Fig. 3. Time evolution of $\theta[\mathrm{K}]$ on the $2 \mathrm{PVU}$ tropopause, at (a) 1 September 06:00 UTC, (b) 1 September 18:00 UTC, (c) 2 September 06:00 UTC, (d) 2 September 18:00 UTC, (e) 3 September 06:00 UTC, (f) 3 September 18:00 UTC, (g) 4 September 06:00 UTC, (h) 4 September 18:00 UTC. Red lines: Cloud water content contours for $1 \times 10^{-5} \mathrm{~kg} / \mathrm{kg}$ at $310 \mathrm{~K}$. Red shaded region: Cloud water content larger than $8 \times 10^{-5} \mathrm{~kg} / \mathrm{kg}$ at $310 \mathrm{~K}$. 
as the streamer moves eastwards, the potential temperature of its lowest part increases from $315 \mathrm{~K}$ to mainly $325 \mathrm{~K}$ (Fig. 3b). This change suggests that non-conservative processes are taking place that influence substantially the structure of the streamer. Concomittently, a large cloud forms east of the streamer and north of the Pyrenees. This period is analysed in details in Sect. 3.3.

During the next $48 \mathrm{~h}$ (Figs. 3c-e), as the streamer continues to move eastwards, its southern part detaches progressively from the polar reservoir and closed isentropic contours progressively appear: at $325 \mathrm{~K}$ on 2 September 06:00 UTC, and at $330 \mathrm{~K}$ on 3 September 06:00 UTC. The eastern side of the streamer is associated with a region of anomalously large potential temperature which overpasses by $25 \mathrm{~K}$ the typical values of the region. This feature is first seen on 2 September 06:00 UTC in conjunction with the presence of a new cloud to the south-east of the above mentionned cloud. On 2 September 18:00 UTC, this potential temperature anomaly and associated clouds have spread out along the side of the streamer and its amplitude has decreased. The anomaly and associated clouds have almost vanished by 3 September 06:00 UTC.

Note that following Griffiths et al. (2000) the formation of clouds on the eastern side of the streamer are likely related to a low-level convective destabilization implied by the presence of the upper-level positive PV anomaly contained in the streamer. This potential instability is then typically released in the presence of orographically forced lifting of the air.

Note also on 2 September 06:00 UTC the anomalously high potential temperature over France, which corresponds to a low PV anomaly above the cloud. This low PV anomaly is thought to be produced by rising air within this cloud, which extends from the surface to the upper troposphere, following the same mechanism as suggested by Wernli and Davies (1997). As air rises in the cloud, PV increases in the cloud's lower part (positive vertical gradient in diabatic heating) and decreases in the cloud's upper part (negative vertical gradient in diabatic heating). The integration of these PV increase and decrease along the rising motion results in a low PV anomaly near the cloud's outflow.

In subsequent times, the cut-off decays as its lowest potential temperature increases from $320 \mathrm{~K}$ to $330 \mathrm{~K}$ between 3 September 06:00 UTC and 4 September 18:00 UTC (Figs. 3e-h).

Aside the streamer and cut-off, the tropopause is rich of secondary structures and filamentations that form and disappear with time. Some of these structures seem related to the presence of clouds and others evolve in a cloud-free environment. In particular, while the dynamics of the eastern edge of the streamer seems deeply influenced by clouds, the western edge, mostly cloud-free, is the theatre of small-scale structures and in particular of the development of a "tropospheric streamer" 5 " on 3 September 18:00 UTC.

\footnotetext{
${ }^{5} \mathrm{~A}$ tropospheric streamer denotes the reverse of a stratospheric
}

3.2 Quantitative estimates of stratosphere-troposphere exchange

Figures 4 and 5 give the sequence of the 12-hourly averaged STT and TST mass fluxes between 1 September 00:00 UTC and 5 September 00:00 UTC. Note that the colour scheme is logarithmic and covers three orders of magnitude of mass flux. The fluxes estimated close to boundaries will not be taken into account here as they may be flawed by the boundary relaxation (see for instance the large TST pattern occuring near the domain's southern boundary on 4 September 12:00-24:00 UTC). We first focus on patterns defined by mass fluxes larger than $1 \times 10^{-3} \mathrm{~kg} \mathrm{~s}^{-1} \mathrm{~m}^{-2}$, as represented in Figs. 4 and 5 by red to green colours.

The synoptic of STT (Fig. 4) follows remarkably well the dynamics of the evolution of the tropopause discussed earlier and STT occurs almost exclusively in the region of the streamer, streamer break-up and cut-off. A first major STT event happens on 1 September 12:00-24:00 UTC (Fig. 4b) where a distinct structure of strong STT is found within the deepest part of the streamer, where the presence of non-conservative processes was suggested. This major event is further discussed in Sect. 3.3. It is followed for $24 \mathrm{~h}$ by an order of magnitude lower STT fluxes in the eastern, cloudy flank of the streamer (Figs. 4c-d). In addition, significant STT can be identified in the break-up region, where the streamer breaks up and isentropes detach progressively from the polar PV reservoir, over most of the first three days from 1 to 3 September (Figs. $4 \mathrm{e}-\mathrm{f}$ ). Note also on 3 September 12:00-24:00 UTC (Fig. 4f), the north-south oriented tongue of STT in the region of the tropospheric streamer. A second major STT event happens for the two days following 3 September 00:00 UTC (Figs. 4e-h) where strong STT occurs around the cut-off low and then underneath it. This exchange pattern is related to the slow decay of the cut-off.

The synpotics of TST (Fig. 5) also follows the dynamics of the streamer, break-up and cut-off, but with smaller flux amplitudes. On 1 September 00:00-12:00 UTC, a TST region can be seen in the tip of the streamer. In the following days, a persistent TST region is present most of the time on the western side of the streamer (Figs. 5b, c, e and f). Significant TST is also found in cloudy region on the east of the streamer on 2 September. Another interesting feature is the TST taking place underneath the cut-off on 3 September 00:00-12:00 UTC, a period where STT is found on the flanks of the cut-off.

Although most of these STT and TST regions are distinctly related to irreversible deformations of the tropopause, the details of physical mechanisms that are responsible for the exchange can be complex and it would be a harduous task to analyse each individual exchange region. In Sect. 3.3, we

streamer, i.e. an elongated pool of tropospheric air with low PV values stretching northwards which can be seen on an isentropic PV map. 

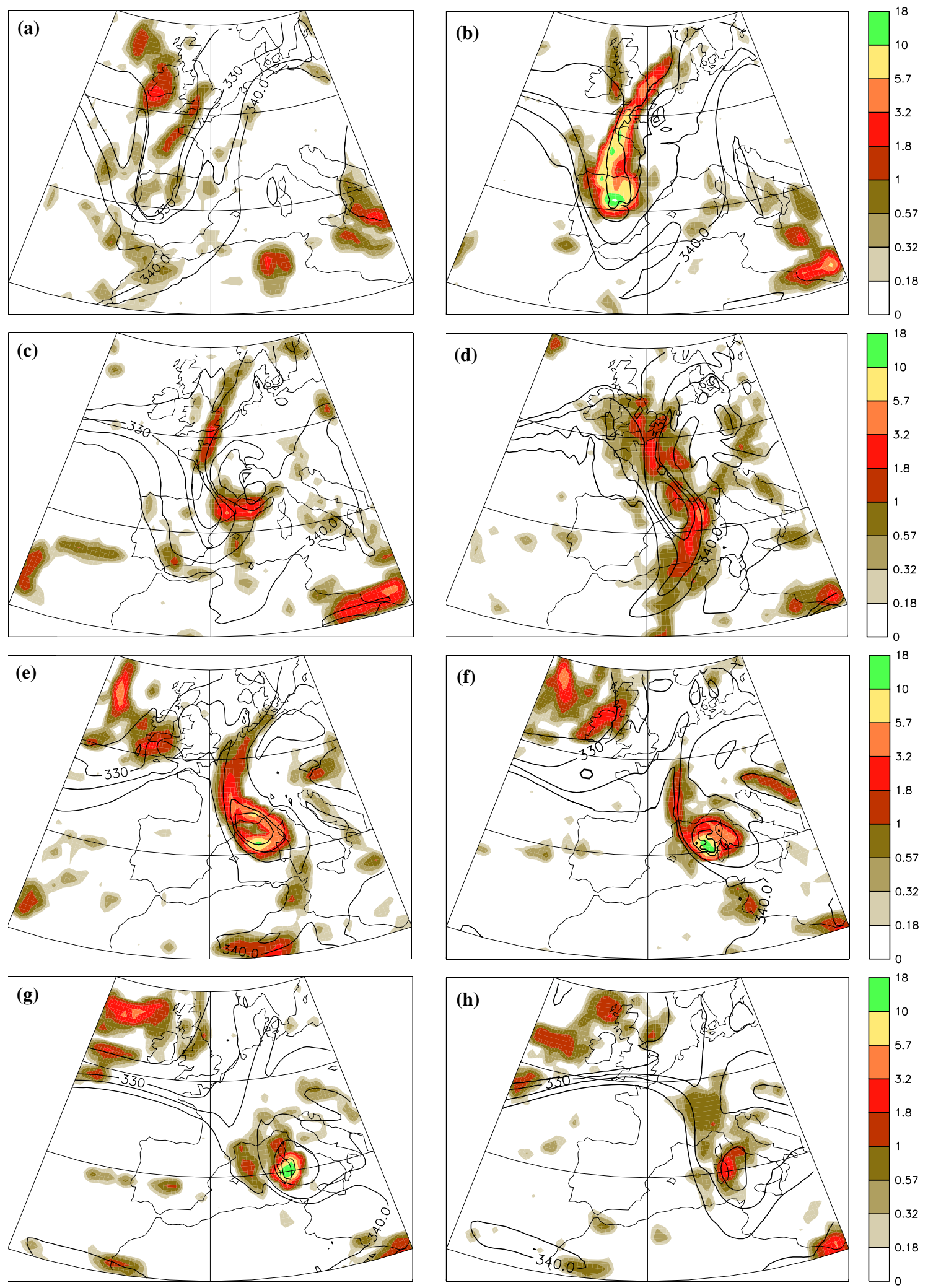

Fig. 4. Time evolution of the estimated STT mass flux, averaged over time intervals of $12 \mathrm{~h}$, in $10^{-3} \mathrm{~kg} \mathrm{~s}^{-1} \mathrm{~m}^{-2}$. The colour scale is logarithmic. (a) 1 September 00:00 12:00 UTC, (b) 1 September 12:00 24:00 UTC, (c) 2 September 00:00-12:00 UTC, (d) 2 September 12:00-24:00 UTC, (e) 3 September 00:00-12:00 UTC, (f) 3 September 12:00-24:00 UTC, (g) 4 September 00:00-12:00 UTC, (h) 4 September 12:00-24:00 UTC. Bold lines represent the 325, 330, 335 and $340 \mathrm{~K}$ isentropic contours on the 2 PVU-tropopause. 

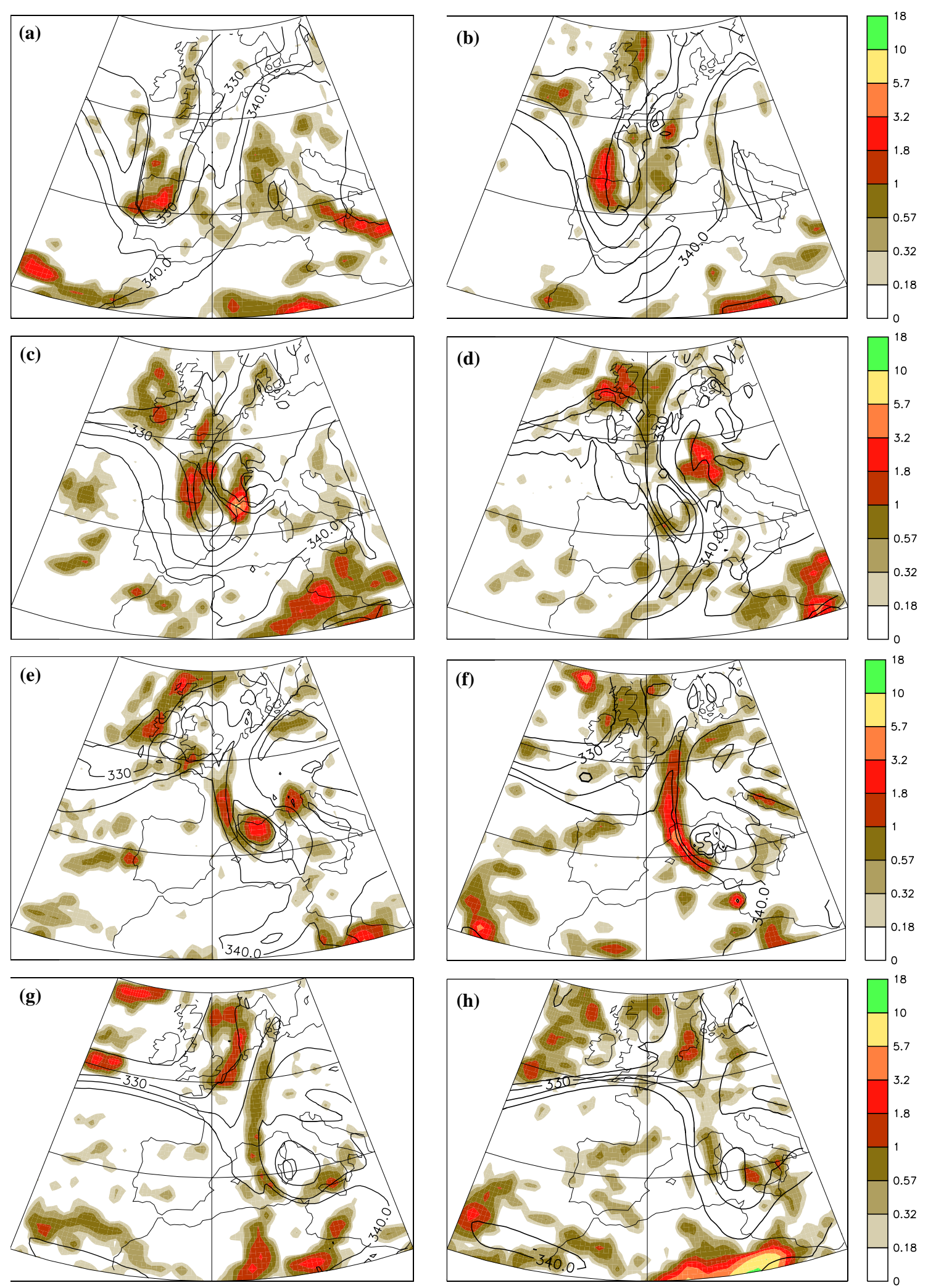

Fig. 5. Time evolution of the estimated TST mass flux, averaged over time intervals of $12 \mathrm{~h}$, in $10^{-3} \mathrm{~kg} \mathrm{~s}^{-1} \mathrm{~m}^{-2}$. The colour scale is logarithmic. (a) 1 September 00:00-12:00 UTC, (b) 1 September 12:00-24:00 UTC, (c) 2 September 00:00-12:00 UTC, (d) 2 September 12:00-24:00 UTC, (e) 3 September 00:00-12:00 UTC, (f) 3 September 12:00-24:00 UTC, (g) 4 September 00:00-12:00 UTC, (h) 4 September 12:00-24:00 UTC. Bold lines represent the 325, 330, 335, $340 \mathrm{~K}$ isentropic contours on the 2 PVU-tropopause. 


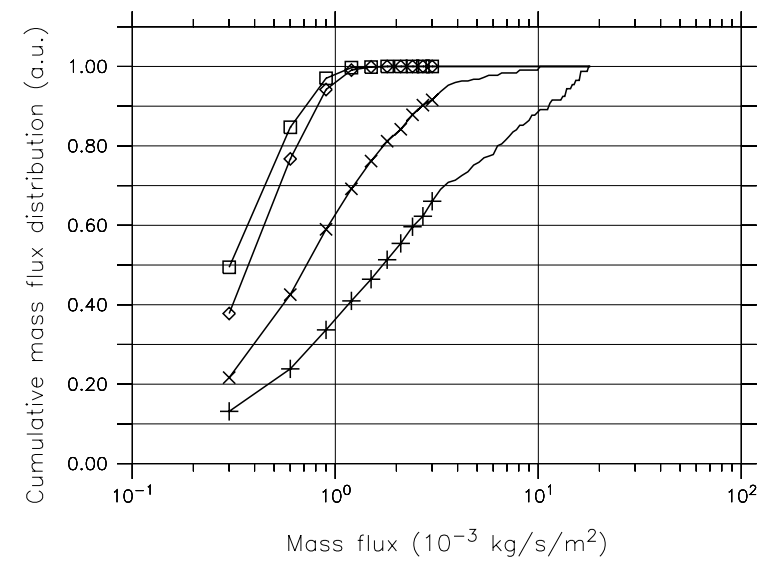

Fig. 6. Cumulative distribution of mass fluxes in individual $1^{\circ} \times 1^{\circ} \times 12 \mathrm{~h}$ gridsquares. Vertical axis is normalized to unity. Horizontal axis is logarithmic in units of $10^{-3} \mathrm{~kg} \mathrm{~s}^{-1} \mathrm{~m}^{-2}$. The first ten points of each curve are highlighted with symbols: + for STT; $\times$ for TST; $\diamond$ for Montecarlo simulation of STT; and $\square$ for Montecarlo simulation of TST (see discussion in text). Integration domain is $10 \mathrm{~W}-20 \mathrm{E}, 38 \mathrm{~N}-58 \mathrm{~N}$.

focus on the 1 September 12:00-24:00 UTC period and show in details the mechanisms by which the strong STT found in the streamer happen.

Aside the patterns of large STT or TST fluxes, exchanges also occur within areas of fluxes smaller than $1 \times 10^{-3} \mathrm{~kg} \mathrm{~s}^{-1} \mathrm{~m}^{-2}$, as shown on Figs. 4 and 5 by the grey shaded areas. These regions of small flux are also relevant as they extend on larger domains. The contribution to the total STT and TST flux of $1^{\circ} \times 1^{\circ} \times 12 \mathrm{~h}$ sectors of given amplitudes of fluxes is shown in Fig 6 . The line with $+(\times)$ symbols represents the cumulative distribution for STT (TST) mass fluxes. The symbols highlight the first ten data points of each line, and the data point increment on the horizontal axis corresponds to one trajectory crossing a $1^{\circ} \times 1^{\circ} \times 12 \mathrm{~h}$ sector $\left(\approx 0.3 \times 10^{-3} \mathrm{~kg} \mathrm{~s}^{-1} \mathrm{~m}^{-2}\right)$. These cumulative distributions show that about $36 \%(63 \%)$ of the total STT (TST) is made of mass fluxes smaller that $1 \times 10^{-3} \mathrm{~kg} \mathrm{~s}^{-1} \mathrm{~m}^{-2}$. These low amplitude mass fluxes are more important than high amplitude mass fluxes in TST. In contrast, STT is dominated by large amplitude mass fluxes, with fluxes as large as $5 \times 10^{-3} \mathrm{~kg} \mathrm{~s}^{-1} \mathrm{~m}^{-2}$ composing as much as $25 \%$ of the total STT (less than 5\% for TST).

For reference, similar cumulative distributions are shown in Fig. 6 from Monte Carlo simulations of the Poisson process where exchange events, independent from each other, are distributed over all $1^{\circ} \times 1^{\circ} \times 12 \mathrm{~h}$ sectors following a uniform random law. The line with $\diamond(\square)$ symbols gives the distribution of the mass flux generated by Monte Carlo simulation with the same total number of exchange events as STT (TST). Note that the difference between the two Monte Carlo simulations is solely related to the ratio $\approx 3: 4$ in total mass flux of TST:STT. Comparison of Monte Carlo results

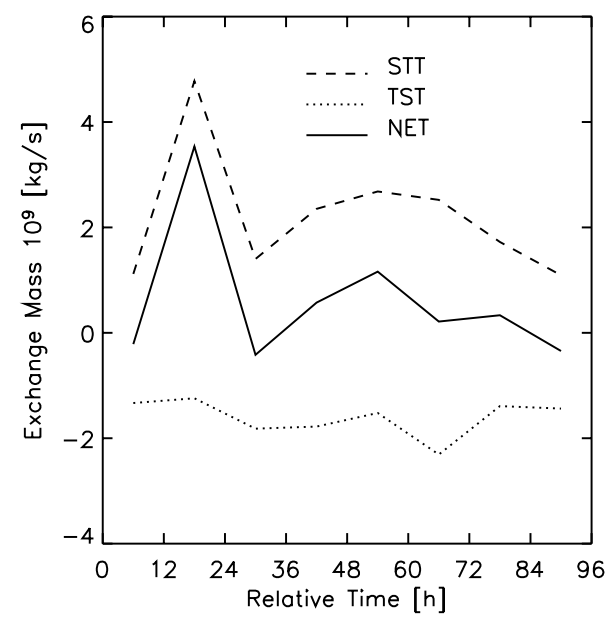

Fig. 7. Time evolution of the total mass exchange in $10^{9} \mathrm{~kg} \mathrm{~s}^{-1}$. Time is relative to 1 September 00:00 UTC. Dashed line is for STT, dotted line for TST and solid line for NET (STT-TST). Integration domain is $10 \mathrm{~W}-20 \mathrm{E}, 38 \mathrm{~N}-58 \mathrm{~N}$.

with STT and TST estimates shows strikingly that both STT and TST are far from behaving like a Poisson process where events are independant and uniformly distributed. In opposition, their incidence is dominated by the physics and dynamics of the tropopause evolution. It also suggests that the difference between STT and TST behaviours, in particular the difference in the rate of convergence towards unity, can not be explained by the statistics of the total number of events alone, but it clearly indicates a difference in the physics and dynamics of STT versus TST. A consequence is that the difference found here between STT and TST may be specific to the baroclinic wave life cycle.

The time evolution of total mass exchange associated with the synoptic development is provided in Fig. 7. The two major STE events mentionned earlier are clearly visible. The total STT associated with the streamer break-up episode is $206 \times 10^{12} \mathrm{~kg}$ ( 1 September 12:00-24:00 UTC), and with the cut-off decay episode $288 \times 10^{12} \mathrm{~kg}$ (3 September 12:00 UTC-4 September 24:00 UTC). These two episodes led to a comparable mass exchange although the rate of exchange peaked in the first one at a level roughly four times larger than the second one. The TST time evolution does not show any major exchange episode, so that the net transport follows roughly the STT time evolution.

For the entire four days period, the overall mass exchange amounts to $763 \times 10^{12} \mathrm{~kg}$ for STT, $554 \times 10^{12} \mathrm{~kg}$ for TST, and $209 \times 10^{12} \mathrm{~kg}$ for the net transport.

\subsection{Analysis of the streamer break-up episode}

We choose to give here an in-depth analysis of the STT event associated with the streamer break-up episode during 1 September 12:00-24:00 UTC, because it is the most explosive exchange episode seen over the period under 


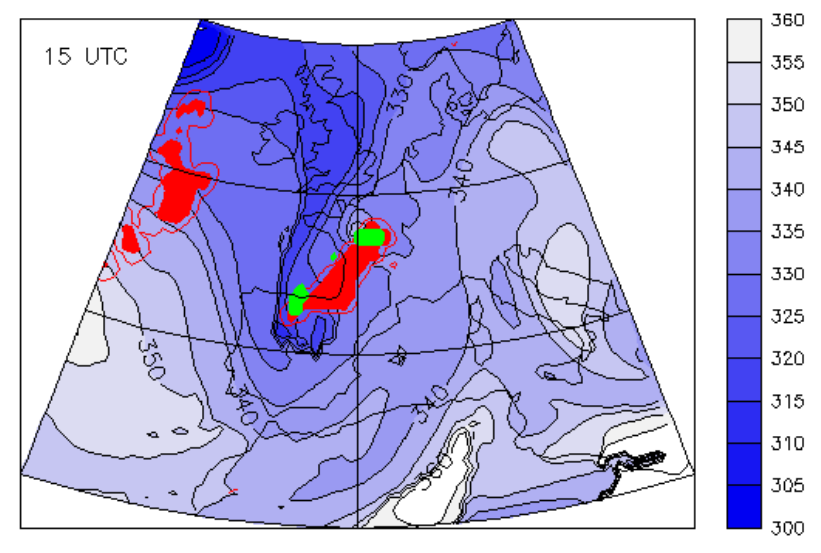

Preview Animation 1. Hourly evolution of $\theta[\mathrm{K}]$ interpolated on the $2 \mathrm{PVU}$ tropopause and cloud water content for the period 1 September 00:00-24:00 UTC. Red lines: Cloud water content equals $1 \times 10^{-5} \mathrm{~kg} / \mathrm{kg}$ at $310 \mathrm{~K}$. Red shaded region: Cloud water content larger than $8 \times 10^{-5} \mathrm{~kg} / \mathrm{kg}$ at $310 \mathrm{~K}$. Green shaded: Cloud water content larger than $1 \times 10^{-5} \mathrm{~kg} / \mathrm{kg}$ at 2 PVU. The Animation is available in the supplemental material: http://www.atmos-chem-phys.net/6/2651/2006/ acp-6-2651-2006-supplement.zip.

investigation. As discussed in the previous section, this massive STT happens mostly at tropopause levels around and below $325 \mathrm{~K}$, where the tropopause potential temperature happened to increase by $5-10 \mathrm{~K}$ (see Figs. 3a, b and Fig. 4b), and to the east of which a large cloud is observed (Fig. 3b).

The hourly evolution of the tropopause and clouds is shown in Animation 1 (see Preview Animation 1 and associated supplemental material: http://www.atmos-chem-phys. net/6/2651/2006/acp-6-2651-2006-supplement.zip) for the period 1 September 00:00-24:00 UTC. Cloud water content at $310 \mathrm{~K}$ is represented in red, while cloud water content at $2 \mathrm{PVU}$ is represented in green. The animation shows that the streamer's erosion starts at 11:00 UTC when the cloud starts to penetrate through the tropopause and continues as long as a cloud is present on the eastern side of the streamer. The non-conservative processes induced by the cloud are clearly responsible for the tropopause break-up and associated STT. Focusing on the formation of the cloud in the animation, it can be observed that in a first phase lasting from 11:00 UTC to 17:00 UTC, the cloud responsible for the streamer break-up is stationary at $5 \mathrm{~W}, 43 \mathrm{~N}$. This is slightly north of the Pyrenees. The cloud develops at this location while the streamer approaches. When the northward circulation induced by the streamer over the Pyrenees is large enough, the associated lifting releases the potential instability and the cloud forms. As the streamer approaches closer to the Pyrenees, the cloud becomes more intense and penetrates through the tropopause. The cloud then disappears when the circulation induced by the streamer above the Pyrenees vanishes and becomes southward. At the same time, a second phase begins, with a new cloud forming on the eastern edge of the streamer around $2 \mathrm{~W}, 45 \mathrm{~N}$, penetrating through the tropopause. This new cloud is non-stationary as it moves eastwards with the streamer, and continues the erosion of the streamer started by the first cloud but at a much slower rate.

More insight in the evolution of the tropopause and location of STT during this explosive episode can be gained from the three-dimensional views provided in Fig. 8: (a) well before (10:00 UTC), (b) near the beginning (14:00 UTC), (c) at the maximum (15:00 UTC), (d) near the end (16:00 UTC), and (e) well after (23:00 UTC) the event. At 10:00 UTC (Fig. 8a), the tropopause penetrates deeply into the troposphere and reaches elevations down to $5-6 \mathrm{~km}$. The intrusion has a smooth vertical flank which rolls up cyclonically at the southern tip. The bottom of the flank is nearly aligned with isentropic surfaces. Then, between 14:00 UTC and 16:00 UTC, the flank is rapidly eroded. An arched structure is progressively formed, leading to a remnant intrusion at the northern boundary and an isolated vertical tube at the southern boundary (Fig. 8d). The streamer break-up coincides temporally with the intense cumulus cloud east of the streamer and north of the Pyrenees. Finally (Fig. 8e), the lower part of the stratospheric tube is entirely mixed and the tropopause resembles its state eleven hours earlier but with a much shallower intrusion. STT and TST trajectories are represented at the exchange time as red and green traces in Fig. 8. There is an excellent agreement between the diagnosed locations of STT events and the zone of erosion of the tropopause.

The hourly evolution of the STT during 1 September 00:00-24:00 UTC is represented in Fig. 9 for various PVlevels. The evolution of STT at 2 PVU reveals that the explosive STT episode essentially lasts for $6 \mathrm{~h}$ between 13:00 and 19:00 UTC, and that during the peak period 15:0016:00 UTC no less than $9 \times 10^{9} \mathrm{~kg} \mathrm{~s}^{-1}$ of mass is transported across the tropopause. The peak period coincides with the time of strongest irreversible deformation of the tropopause seen in Fig. 8. This excellent correspondance between the three-dimensional structures of the tropopause and the hourly evolution of STT gives further credit to the method used here.

Figure 9 also provides the STT mass flux as estimated across other iso-PV surfaces from 1.5 to $5 \mathrm{PVU}$. The peak mass flux decreases with higher PV-levels as expected, except between 1.5 and 2 PVU. Furthermore, the peak period starts earlier at PV levels above or at 2.5 PVU than below, and a particularly marked lag is seen between the $2.5,2$ and 1.5 PVU levels. This suggests that non-conservative processes initiated by the cumulus cloud are felt sooner at high PV-levels than below 2.5 PVU.

The synoptics of the exchange mass flux across 1.5, 2, 3 and 4 PVU iso-PV surfaces is shown in the left panels of Fig. 10 for the time interval 1 September 12:0024:00 UTC, together with isentropes and cloud water content at 1 September 13:00 UTC when peak STT is happening at 2.5 PVU and above. STE is occuring exclusively in the re- 


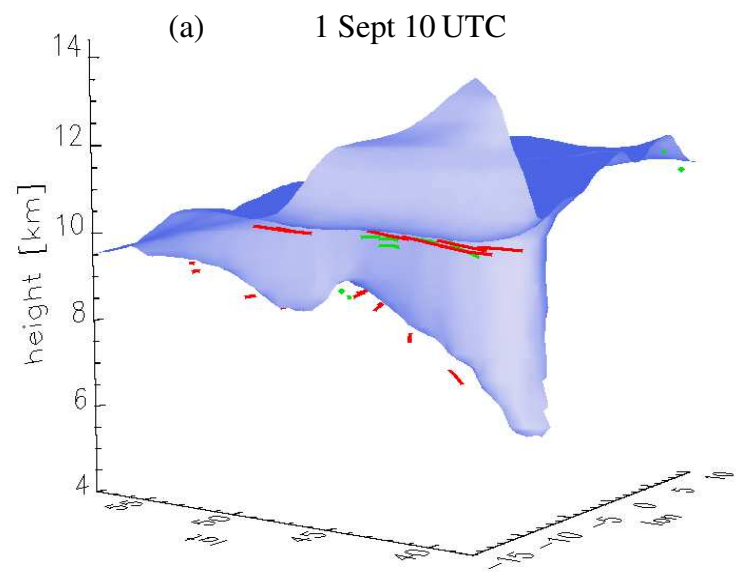

(c)

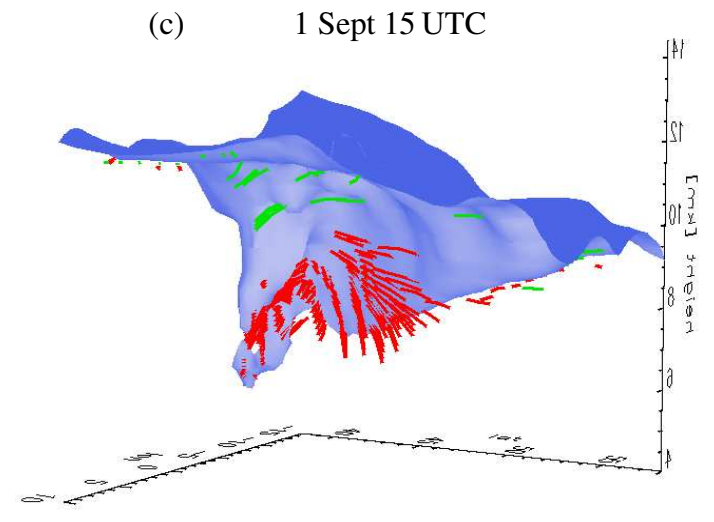

(e)

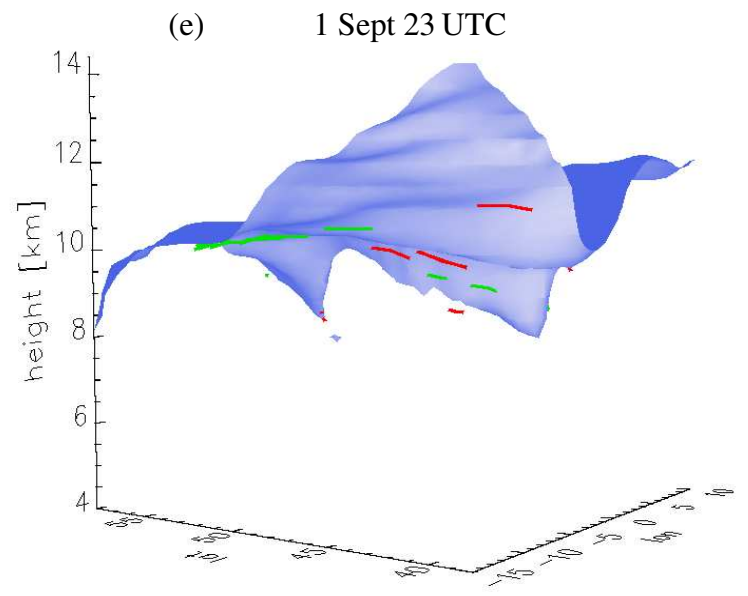

(b) 1 Sept 14 UTC

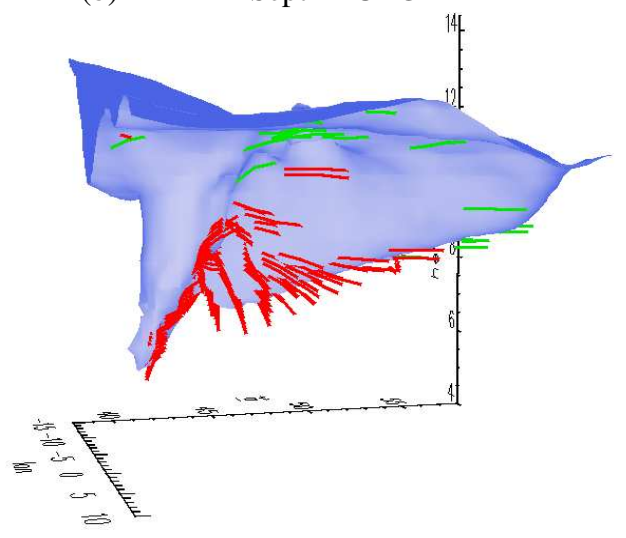

(d)

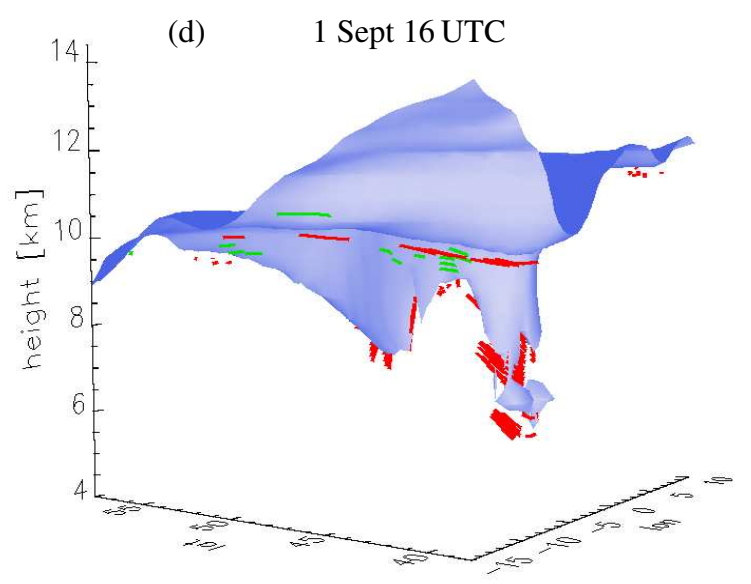

Fig. 8. Three-dimensional view of selected instants during the break-up phase on 1 September. Blue surface: 2 PVU tropopause in the domain $15 \mathrm{~W}-15 \mathrm{E}, 35 \mathrm{~N}-58 \mathrm{~N}$, and vertically from 4 to $16 \mathrm{~km}$. Red (green) traces are portions of STT (TST) trajectories. The traces show three consecutive trajectory segments of one hour each, the middle one corresponding to the exchange location. (a) 10:00 UTC, view from the south-west, (b) 14:00 UTC from south-east, (c) 15:00 UTC from south-east, (d) 16:00 UTC from south-west, (e) 23:00 UTC from south-west. 


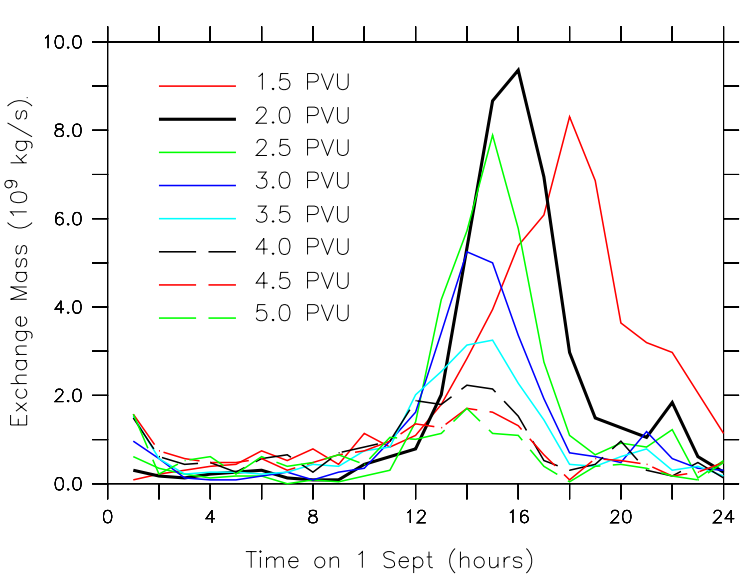

Fig. 9. Hourly evolution of the STT mass flux at various PV levels for the period 1 September 00:00-24:00 UTC within the zone of large STT associated with the streamer break-up (see Fig. 4b). Mass flux is in units of $10^{9} \mathrm{~kg} \mathrm{~s}^{-1}$, integrated over the domain $10 \mathrm{~W}-0 \mathrm{E}$, $39 \mathrm{~N}-50 \mathrm{~N}$.

gion of the streamer with a magnitude decreasing with the PV level, and is largely dominated by STT transport during this period. The cloud water content decreases also with the $\mathrm{PV}$ level, though a weak sign of it remains present at $4 \mathrm{PVU}$.

The right panels of Fig. 10 show the averaged diabatic heating rate experienced by STT trajectories while they cross the corresponding iso-PV surface. The diabatic heating rate is estimated by calculating the potential temperature change along STT trajectories between the two consecutive time steps embedding the exchange time. At levels 1.5 and $2 \mathrm{PVU}$, the cloud clearly marks a separation between the northern region with negative diabatic heating rates and the southern region with positive and relatively stronger diabatic heating rates. Note that in the southern part, air parcels rise in terms of potential temperature while they descend in terms of PV. This particular geometry is possible due to the quasi-vertical orientation of iso-PV surfaces in the streamer's tip. The difference in the sign of diabatic heating between the northern and southern side of the cloud is related to the vertical location of the exchange with respect to the cloud. For instance, STT across 2 PVU takes place in average between 360 and $420 \mathrm{hPa}$ in the streamer's tip, whereas it takes place in average between 320 and $360 \mathrm{hPa}$ on the northern side of the cloud. This suggests that the positive heating rates reflect the latent heat release in the region of the cloud, whereas the negative heating rates reflect the cloud top radiative cooling. This also suggests that there is an overall region of negative vertical gradient of heating where STT takes place, whatever the actual sign of the heating, in a consistent manner with the theoretical expression of the material rate of PV. This overall negative vertical gradient appears clearly in Fig. 11. A direct consequence of this is that the height of maximum diabatic heating in the cloud sets the lower boundary for cloudinduced STT.
The region of positive heating rates seen at 1.5 and $2 \mathrm{PVU}$ levels, becomes very small at 3 PVU and disappears at 4 PVU (Fig. 10), because the cloud diabatic heating vanishes at these heights (Fig. 11). By contrast, the cloud top cooling penetrates at least up to $5 \mathrm{PVU}$ and the region of negative heating rates is seen instantly at all PV-levels in the streamer's body.

Animation 2 (see preview of Animation 2 and associated supplemental material: http://www.atmos-chem-phys. net/6/2651/2006/acp-6-2651-2006-supplement.zip) follows the material motion of air parcels during their travel from the stratosphere to the troposphere. The air parcels shown here are selected to cross the 2 PVU tropopause in the streamer's tip at the peak exchange time 1 September 14:00 UTC. In addition to the spatial trajectories, the temporal evolution of $\mathrm{PV}$ and $\theta$ are shown for the fifteen hours before and after exchange. This animation shows that air parcels descend rapidly in the stratospheric intrusion while keeping their PV and $\theta$ mostly constant in a first step. Then, as they approach the exchange location, their average PV decreases and $\theta$ increases. The presence of the cloud starts to influence the motion of air parcels about three hours before they cross the tropopause. During this period, individual trajectories seem to follow the average evolution as far as PV is concerned. But individual $\theta$ evolutions show that uppermost trajectories continue with unchanged $\theta$ until after the tropopause is crossed, while the lower set starts the $\theta$-ascent three hours before the exchange. Hence, the negative vertical heating gradiant is again apparent here.

Finally, the simplicity of PV and $\theta$ evolutions along trajectories contrasts the apparent complexity of the tropopause structure evolution. This points also to the relative simplicity to detect STE using this Lagrangian approach. In contrast, the Eulerian evaluation of the mass flux through the tropopause surface may prove difficult when the tropopause is complex and full of structures, a situation which is typical of such large STE events.

\section{Sensitivity analyses}

\subsection{Sensitivity to data resolution}

The STE flux estimates described in the previous section have been repeated for various data resolutions obtained by degradation of the original data set $\left(0.5^{\circ} \times 0.5^{\circ} \times 1 \mathrm{~h}\right)$. All trajectories as well as the tropopause have been re-computed using the coarser, degraded data. This method allows to keep exactly the same meteorological evolution at every resolution. The temporal evolution of total cross-tropopause mass flux for the various data resolutions is shown in Fig. 12 separately when degrading space and time resolutions.

The STT results show a clear response to varying spatial resolutions. While the $0.5^{\circ}$ and $1^{\circ}$ resolutions lead roughly to similar results, the $2^{\circ}$ resolution produces a strong underestimate of STT during the break-up phase as well as the late 

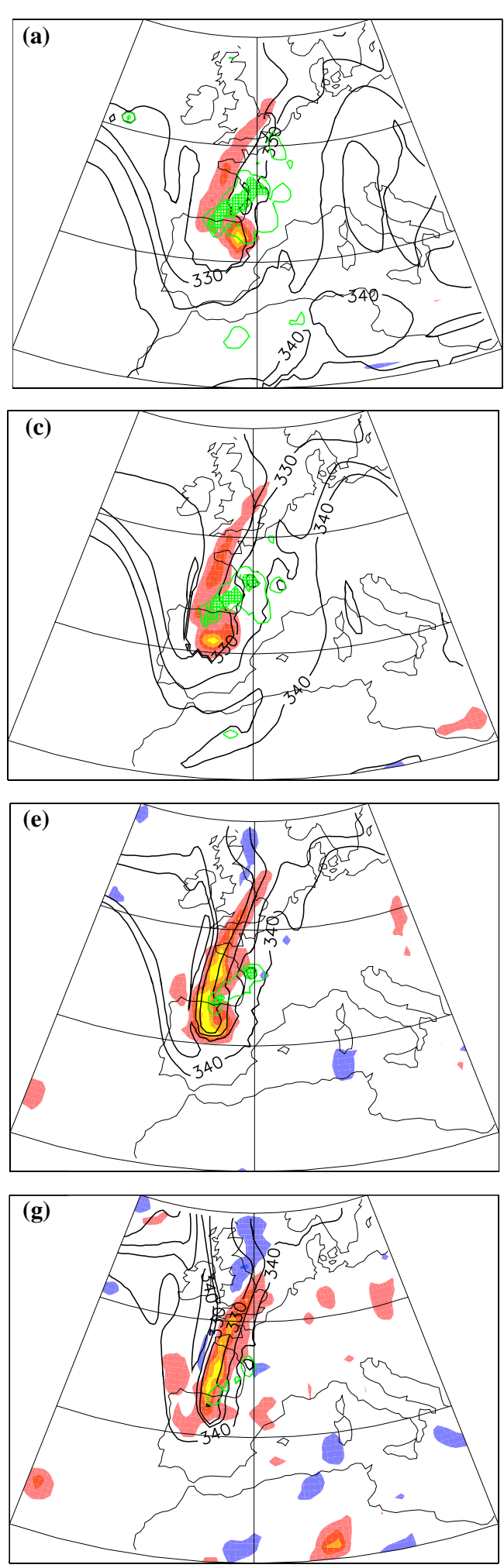
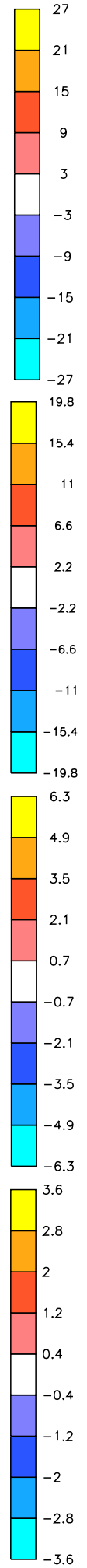
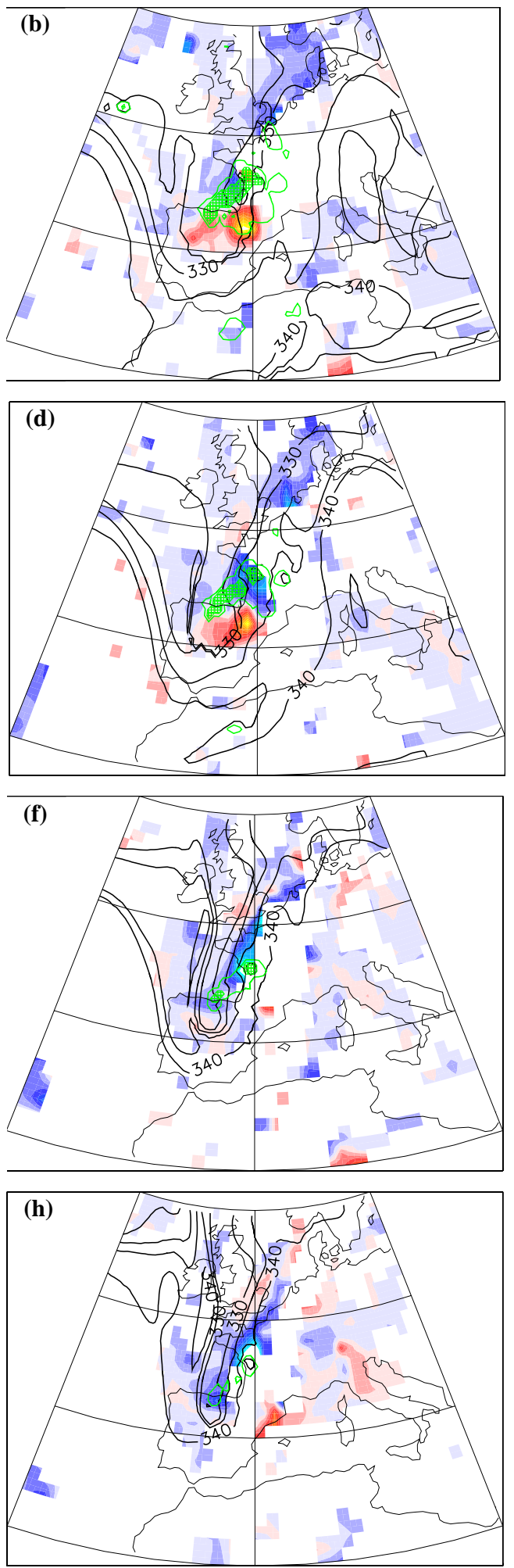

Fig. 10. Left: Estimated net mass flux (STT-TST), for the period 1 September 12:00-24:00 UTC, in $10^{-3} \mathrm{~kg} \mathrm{~s}^{-1} \mathrm{~m}^{-2}$, across different iso-PV surfaces: (a) $1.5 \mathrm{PVU}$, (c) $2 \mathrm{PVU}$, (e) $3 \mathrm{PVU}$, (g) 4 PVU. Right: Diabatic heating rates (K/h) calculated at the exchange location by differentiating the potential temperature along each trajectory. Bold lines represent the $325,330,335$ and $340 \mathrm{~K}$ isentropic contours at the corresponding PV surface on 1 September 13:00 UTC. Green lines: Cloud water content contours for $0.05 \times 10^{-5}$ at the corresponding PV surface at 13:00 UTC. Green shaded regions: Cloud water content larger than $1 \times 10^{-5} \mathrm{~kg} / \mathrm{kg}$ at the corresponding PV surface at 13:00 UTC. 


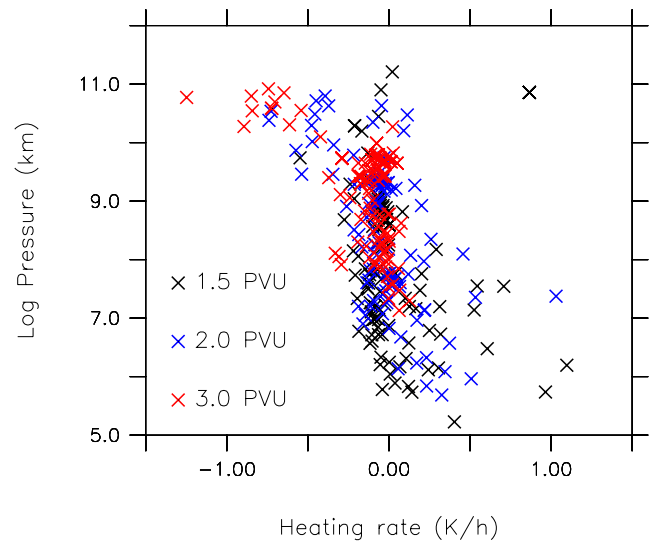

Fig. 11. Scatter plot of the local diabatic heating rate $(K / h)$ of STT corresponding to Figs. 10b, d, f, as a function of the log pressure height $(\mathrm{km})$. Black: 1.5 PVU; Blue: 2 PVU; Red: 2.5 PVU. Domain: $10 \mathrm{~W}-0 \mathrm{~W}, 39 \mathrm{~N}-50 \mathrm{~N}$.

cut-off decay phase. This underestimate is obviously due to a too coarse representation of the tropopause deformation. A slight underestimate of STT in the late cut-off decay phase is also seen with the $1^{\circ}$ resolution, which indicates that structures of a scale smaller than $1^{\circ}$ contribute to the cut-off decay, though to a small extent. TST estimates do not show a clear response to the degradation of spatial resolution. The $1^{\circ}$ resolution produces substantially larger values, while the $2^{\circ}$ resolution gets a very different temporal structure. This unexpected response is thought to be caused by the simple data degradation scheme which carries forward the variability of the wind held in the highest resolution data to the lower resolution data, without filtering small scales. This effect may be particularly pronounced where small scale variability is important, such as in the tropospheric vertical wind, resulting in overestimated TST in the degraded data. The resulting net flux shows a reduced magnitude at low spatial resolutions, but keeps its gross temporal structure. The total net mass flux over the whole period of $96 \mathrm{~h}$ is very sensitive to the horizontal resolution: $209 \times 10^{12} \mathrm{~kg}$ at $0.5^{\circ}$ resolution, $27 \times 10^{12} \mathrm{~kg}$ at $1^{\circ}$, and $-15 \times 10^{12} \mathrm{~kg}$ at $2^{\circ}$.

The exchange flux is also affected by the temporal resolution. Compared to the $1 \mathrm{~h}$ resolution, the STT is slightly overestimated during the late cut-off decay phase at the $3 \mathrm{~h}$ resolution, while it is increased by a quasi-constant noise at the $6 \mathrm{~h}$ resolution. The TST responds in a similar way. The noise introduced in both STT and TST mostly cancels in the net mass flux, and thanks to this symmetry, the effect of the temporal resolution on the total net mass flux is reduced: $209 \times 10^{12} \mathrm{~kg}$ at $1 \mathrm{~h}$ resolution, $138 \times 10^{12} \mathrm{~kg}$ at $3 \mathrm{~h}$ resolution, and $128 \times 10^{12} \mathrm{~kg}$ at $6 \mathrm{~h}$ resolution. Note that the latter considerations on the temporal resolution also hold for a spatial resolution of $1^{\circ}$ instead of the $0.5^{\circ}$ (not shown).

\subsection{Sensitivity to threshold residence time}

The spatial smoothening of the tropopause, consequence of the derivation of PV from finite resolution data, and the interpolations within the trajectory calculation scheme are suspected to produce oscillations of trajectories around the tropopause even if the flow is PV-conservative. This may introduce lots of spurious exchange events with rather short residence times. Some information on these spurious events can be gained by hypothesizing that lowering the spatial resolution increases the smoothening of the tropopause, and hence increases the number of spurious exchange events.

Extra trajectory calculations were carried out to minimize the effect of trajectory length on this analysis. For every data resolution, $90 \mathrm{~h}$ long trajectories were started from our usual starting grid forward in time on 1 September 00:00 UTC and backwards on 4 September 18:00 UTC. The distributions of time intervals between two successive cross-tropopause events along these trajectories, both happening within the simulation domain, are shown in Fig. 13. Obviously, the general shape of the distributions are strongly constrained by the length of trajectories and the requirement that successive crossing points must be within the simulation domain. To account for this constraint and other possible effects of the system, we use the $0.5^{\circ}, 1 \mathrm{~h}$ resolution distribution as reference distribution. Compared to this reference distribution, the distributions for lower spatial resolutions with $1 \mathrm{~h}$ temporal resolution show increased frequencies of interval times smaller than about $8 \mathrm{~h}$. In contrast, the effects of lower temporal resolutions is a truncation of the distribution of time intervals lower than about the temporal resolution itself. At time intervals larger than $8 \mathrm{~h}$, the different distributions converge remarkably well.

This result justifies the hypothesis that lowered spatial resolutions induce more spurious cross-tropopause events. And furthermore, it shows clearly that spurious events can be removed to a large extent by setting a threshold residence time larger than $8 \mathrm{~h}$.

The dependence with the threshold residence time of the temporal evolution of STE for the highest data resolution is shown in Fig. 14. Note that a maximum transition time $T_{\max }^{\text {trans }}=6 \mathrm{~h}$ was used for all experiments with $\tau^{*} \geq 12 \mathrm{~h}$, while no transition time was used for $\tau^{*}=0$. A confirmation of the ability of the residence time criterion to remove properly spurious events comes from the comparison of STE estimates with $\tau^{*}=12 \mathrm{~h}$ and without residence time criterion. In effect, although the raw STE fluxes are three to five times larger than the STE fluxes with $\tau^{*}=12 \mathrm{~h}$, and although the temporal evolution differ strongly, the net fluxes are very similar. This demonstrates that a large number of exchange events in the raw STE fluxes are associated with residence times smaller than $12 \mathrm{~h}$ which cancel each other in the net flux at each time step. The cross-tropopause flux estimated with the residence time criterion preserves the relevant exchange 


\section{PV ard Theti along the trojectories}
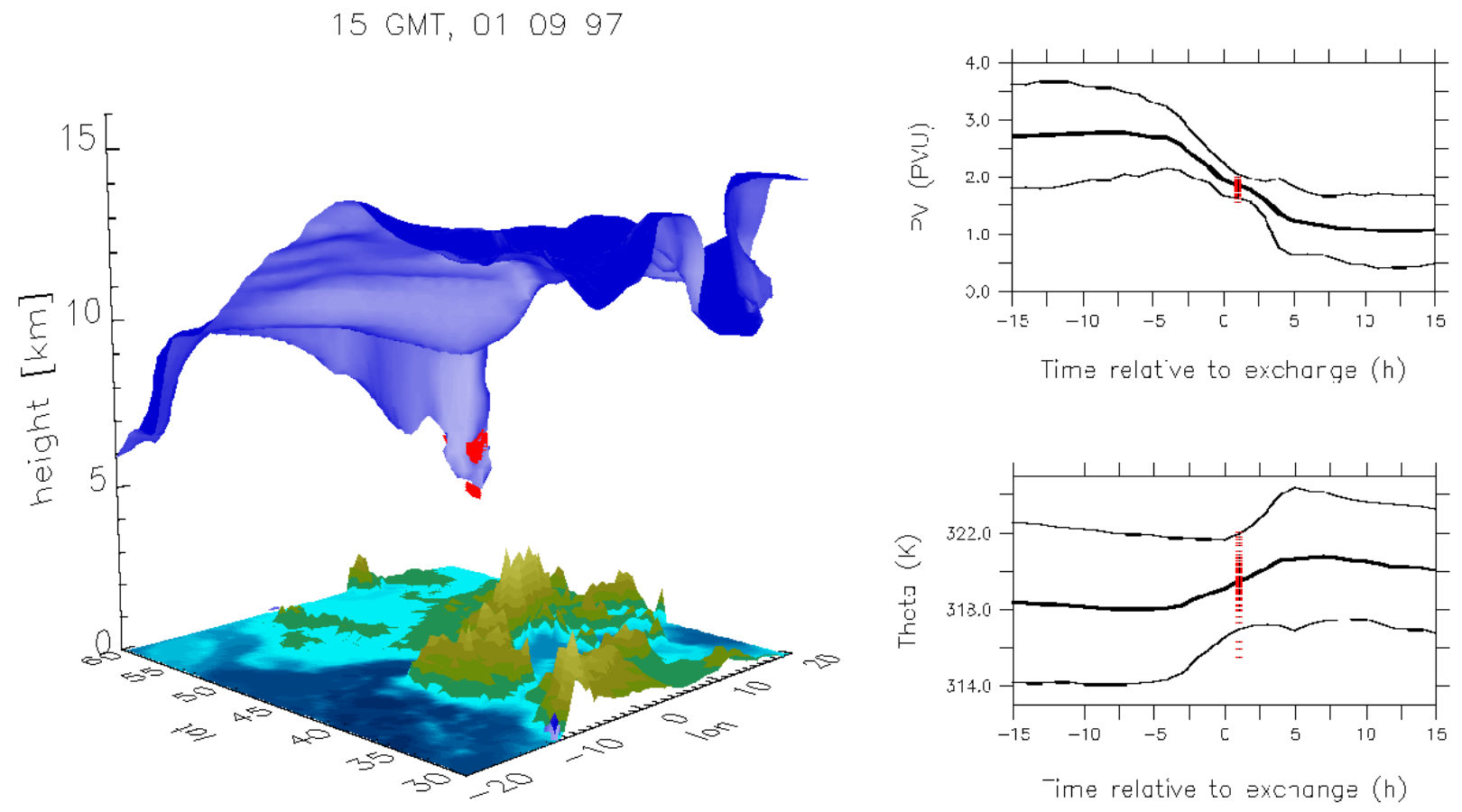

Preview Animation 2. Left: Three-dimensional animation of the 2 PVU tropopause (blue surface) and trajectories of air parcels selected to cross the tropopause in the domain $6 \mathrm{~W}-2 \mathrm{~W}, 40 \mathrm{~N}-43 \mathrm{~N}, 600-400 \mathrm{hPa}$, on 1 September 14:00 UTC. Upper right: Evolution of PV along the selected trajectories within $\pm 15 \mathrm{~h}$ of exchange time. Bold line denotes the average over the set of trajectories, solid lines mark the two standard deviations range and red traces show individual trajectories. Lower right: Same as upper right, but for the evolution of $\theta$. The Animation is available in the supplemental material: http://www.atmos-chem-phys.net/6/2651/2006/acp-6-2651-2006-supplement.zip.

fluxes, and leads to a net flux which is of the same order of magnitude as the individual STT and TST.

For $\tau^{*} \geq 12 \mathrm{~h}$, the dependence of the STE fluxes on $\tau^{*}$ is smaller and is more or less constant throughout the temporal evolution. Slightly different dependences on $\tau^{*}$ can nevertheless be seen, as for instance in the begining of the cutoff decay, where fewer short residence times than average are present in the STT. This illustrates how non-conservative forces within a finite layer around the tropopause influences the cross-tropopause mass flux when estimated as a function of $\tau^{*}$.

Note finally that the problem of spurious exchange events in estimated STE fluxes is not specific of the Lagrangian approach, but also pertains, in a similar way, to the Eulerian approach. In effect, the Eulerian approach couples time derivatives with spatial derivatives of finite resolution data and this way introduces spurious exchange fluxes. However, the direct control on these spurious events using a threshold residence time is specific to the Lagrangian approach.

\subsection{Dependence on the PV-tropopause definition}

The STE mass flux differs significantly depending on the applied tropopause definition. An illustration of this was discussed in Sect. 3.3 in the context of the explosive erosion of the streamer. Here, we discuss the dependence of STT and TST on the PV-level globally for the range between 1.5 and 5 PVU.

Figure 15 shows the temporal evolution of STT, TST and NET mass fluxes. In general, for both STT and TST, the mass flux decreases monotonically with the PV level, but the way the flux changes over time is clearly different at different PV level and depends on the synoptic detail. In particular, the pattern of two large STT maxima, at 1 September 12:0024:00 UTC associated with the explosive streamer erosion and later during the cut-off decay, occurs only at levels below 4 PVU. Above 4 PVU, a different, flatter temporal evolution is seen, with largest STT taking place during the period 1 September 12:00 UTC-3 September 00:00 UTC. This evolution is dominated by the break-up of the streamer, with insignificant STT at the streamer's tip and during the decay 

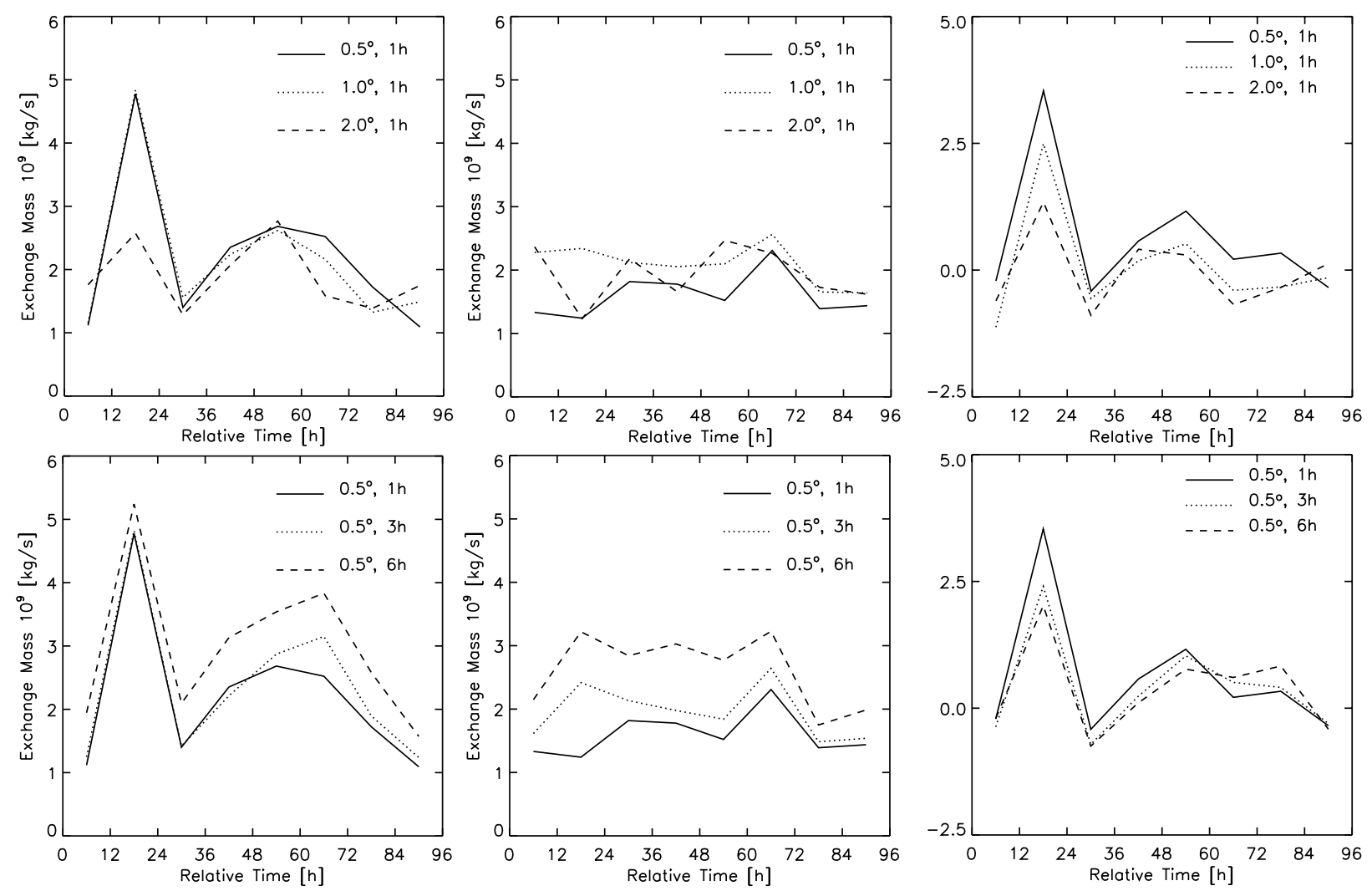

Fig. 12. Total mass flux for various data resolutions. Left: STT. Middle: TST. Right: NET. Top: Varying spatial resolution. Bottom: Varying time resolution. Time is relative to 1 September 00:00 UTC, and units are: $10^{9} \mathrm{~kg} \mathrm{~s}^{-1}$. Integration domain is $10 \mathrm{~W}-20 \mathrm{E}, 38 \mathrm{~N}-58 \mathrm{~N}$.

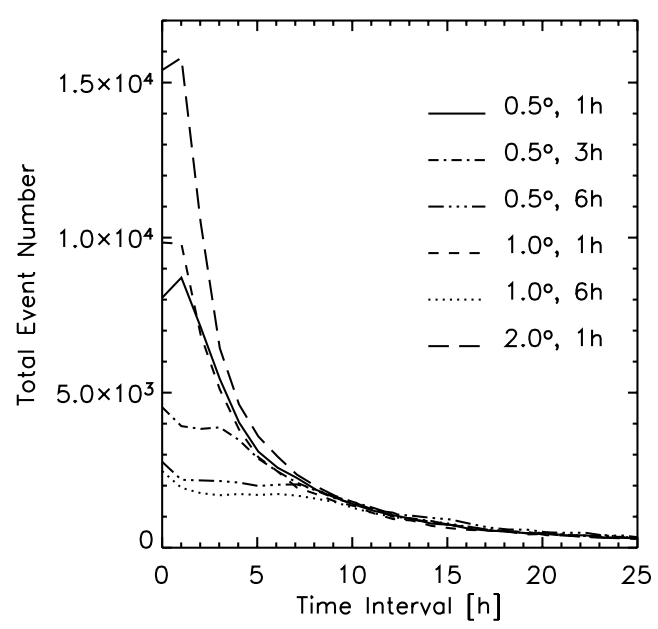

Fig. 13. Distributions of time intervals between two successive cross-tropopause events along trajectories, both happening within the simulation domain. Trajectories are computed for $90 \mathrm{~h}$ from the usual starting grid forwards from 1 September 00:00 UTC and backwards from 4 September 18:00 UTC. The different line types show calculations with different data resolutions. of the cut-off. The NET mass flux shows also a strong contrast between the levels below 4 PVU, where the break-up and cut-off decay phases are captured, and the levels above, again dominated by the 1 September 12:00 UTC-3 September 00:00 UTC period.

An important consequence is that the $4 \mathrm{PVU}$ surface can not be considered as a proxy of PV levels underneath as far as STE is concerned.

\section{Conclusions}

In this study, the STE mass flux was estimated within a typical baroclinic wave breaking event and subsequent cutoff decay using a method adapted from Wernli and Bourqui (2002). The detailed analysis of STE associated with the event illustrated how fine temporal and spatial flow structures can lead to large mass fluxes across the tropopause. In particular we showed the explosive nature of the streamer breakup, which happened over a period no longer than $4-6 \mathrm{~h}$. The two phases of the synoptic evolution that are the break-up and the cut-off decay were found to contribute to a similar extent in the total exchange mass flux.

A comparison of our results with other published estimates is shown in Table 1. Our estimates are of comparable 

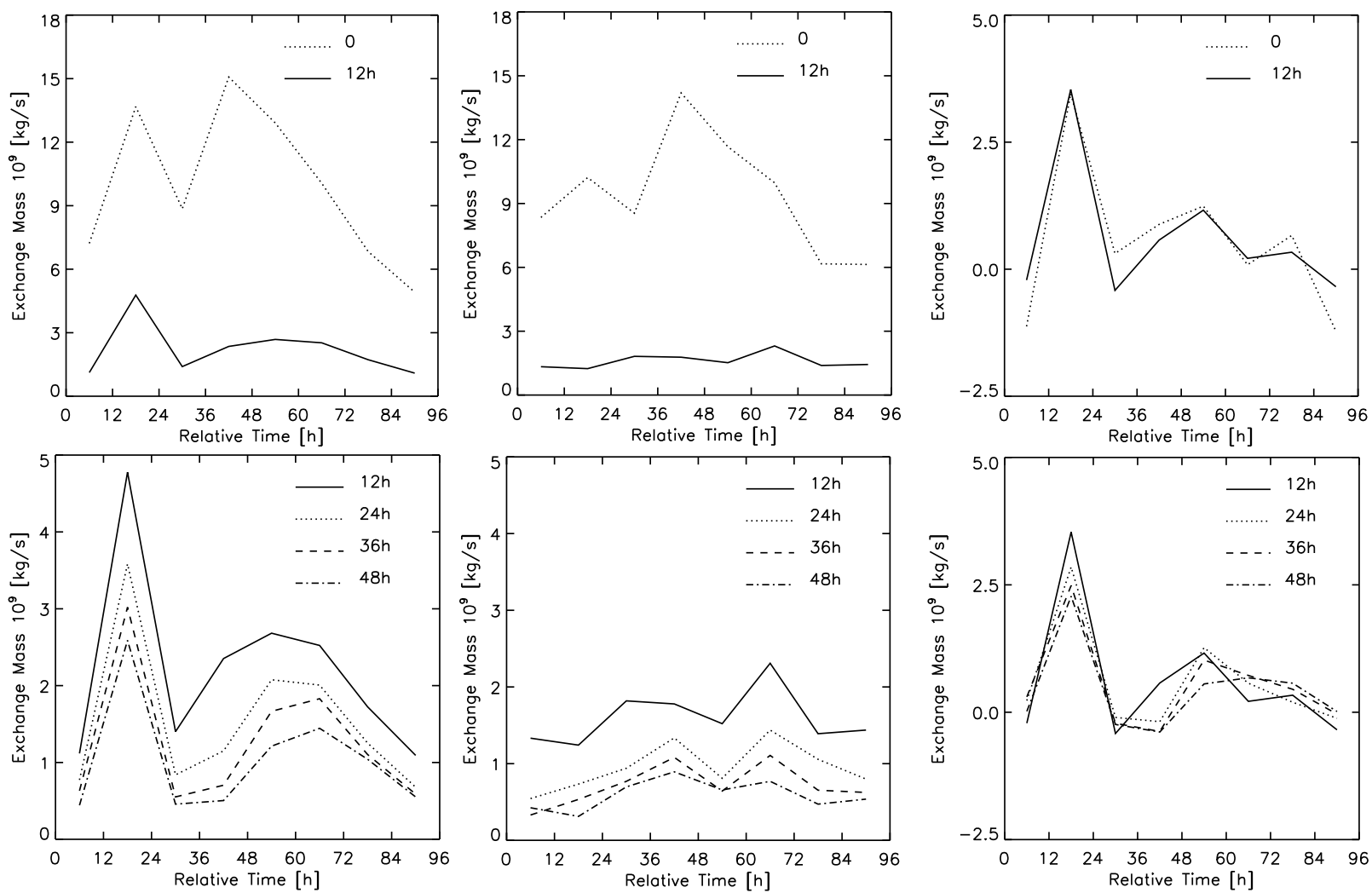

Fig. 14. Total mass flux for various threshold residence times $\tau^{*}$. Left: STT. Middle: TST. Right: NET. $\tau^{*}=0$ denotes absence of residence time criterion. Time is relative to 1 September 00:00 UTC, and units are: $10^{9} \mathrm{~kg} \mathrm{~s}^{-1}$. Integration domain is $10 \mathrm{~W}-20 \mathrm{E}, 38 \mathrm{~N}-58 \mathrm{~N}$.
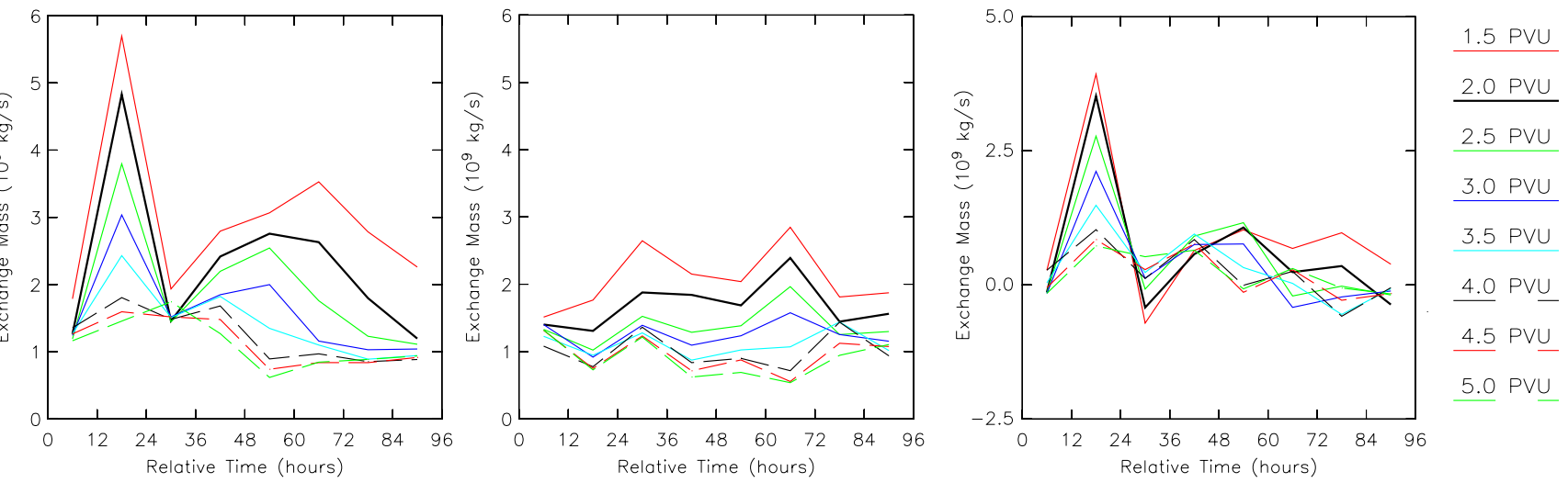

Fig. 15. Total mass flux across various iso-PV surfaces estimated with $\tau^{*}=12 \mathrm{~h}$. Left: STT. Middle: TST. Right: NET. Time is relative to 1 September 00:00 UTC, and units are: $10^{9} \mathrm{~kg} \mathrm{~s}^{-1}$. Integration domain is $10 \mathrm{~W}-20 \mathrm{E}, 38 \mathrm{~N}-58 \mathrm{~N}$.

magnitude, though rather on the lower edge of the range of estimates of these other studies. A reason for having relatively small values may come from the threshold residence time, which filters out the part of the mass flux associated with residence times smaller than $12 \mathrm{~h}$. Another reason may come from the absence of explicit sub-grid scale physics in the advection of trajectores. However, it must be emphasized that the variety of synoptic situations, seasons, and the sizes of domains and time windows over which mass fluxes are averaged are all factors which, beside the other uncertainties lying in methodologies, contribute to enlarge the range of estimates.

The comparison of the total mass flux obtained in this case study with the autumn mass flux in the European sector of Wernli and Bourqui (2002) suggests that tropopause perturbations like the one studied here may just follow one another every 3-5 days on average, and this way, produce frequent, episodical transport of mass across the tropopause. 
Table 1. STE mass flux estimates from published case studies using different diagnostic methods, in $10^{14} \mathrm{~kg} /$ day over the region of interest. The data used are either operational analysis data or model outputs. Method types: (1) methods based upon Eulerian formulations of the cross-tropopause flux using the mentioned vertical coordinate; (2) methods explicitely estimating the non-advective part of the motion of the tropopause; (3) the methods using a trajectory-based Lagrangian representation of the flow; (4) the methods using transport schemes with physics parameterizations and estimating the cross-tropopause transport of a tracer.

\begin{tabular}{|c|c|c|c|c|c|}
\hline Author & Method & Trop & STT & TST & NET \\
\hline Lamarque and Hess (1994) & type 2 & 2 PVU & 5.9 & 4.7 & 1.2 \\
\hline Wernli and Davies (1997) & type 3 & 2 PVU & 1.7 & 0.7 & 0.9 \\
\hline \multirow[t]{4}{*}{ Wirth and Egger (1999) } & type 2 & 4 PVU & 2.2 & 0.7 & 1.5 \\
\hline & type $1(\mathrm{PV})$ & & 2.1 & 0.5 & 1.6 \\
\hline & type $1(\mathrm{p})$ & & 2.9 & 1.9 & 1.0 \\
\hline & type $1(\theta)$ & & 3.8 & 2.0 & 1.8 \\
\hline Kowol-Santen et al. (2000) & Type 3 & $2 \mathrm{PVU}$ & 28.7 & 19.7 & 9 \\
\hline Gray (2003) & type 4 & 2 PVU & 7.0 & - & - \\
\hline \multirow[t]{2}{*}{ Present study } & type 3 & $2 \mathrm{PVU}$ & 1.9 & 1.4 & 0.5 \\
\hline & & 4PVU & 1.1 & 0.8 & 0.3 \\
\hline
\end{tabular}

The analysis of the sensitivity of the method to key parameters led to the following conclusions:

Data resolution: The sensitivity to data resolution was investigated by simple degradation of data resolution. This approach was used to keep exactly the same meteorological evolution for the different resolutions. Although the results found here apply to estimates using similarly degraded data, which is frequent in particular when using (re-)analysis data sets, they may not be completely transposable to modelgenerated low resolution data. The sensitivity to the spatial resolution arises mostly from the scale required to correctly represent the processes that play relevant roles. A data resolution of $1^{\circ} \times 1^{\circ}$ is found to give correct estimates of STT, and a resolution of $2^{\circ} \times 2^{\circ}$ is found to be too coarse. This result is in agreement with Gray (2003). The large sensitivity of TST to spatial resolution is thought to be caused by the data degradation method and needs to be further studied. The sensitivity to temporal resolution showed that a nearly constant noise was introduced at the $6 \mathrm{~h}$ resolution in both STT and TST, which mostly cancels in the net flux.

Threshold residence time: The residence time analysis shows that spurious events are largely associated with residence times smaller than $8 \mathrm{~h}$. Although the spurious events are moslty symetrical between STT and TST, and hence cancel out in the NET mass flux, they can lead to a dramatic overestimate of the chemical effect of STE. A minimum residence time threshold of $8 \mathrm{~h}$ is therefore recommended. The possibility of removing spurious events in an efficient manner gives to the method an interesting advantage over other methods. It was also shown that STT and TST fluxes are associated with continuous distributions of residence times which can vary depending on the synoptics near the tropopause. As a consequence, there is no unique choice for the threshold residence time, and larger values of $\tau^{*}$ can be used to emphasize more significant exchanges. Moreover, the dependence of STE mass fluxes with the threshold residence time has potential implications on the chemistry which need to be studied in details.

$P V$-level tropopause: STE estimates showed a significant dependence with the choice of the PV-level as a consequence of the different contributions of processes at different heights. In particular, a marked transition was found in the global evolution at 4 PVU. Hence, the 4 PVU surface can not be used as a proxy for lower iso-PV surfaces, and vice-versa.

Acknowledgements. The author wishes to thank H. Wernli and H. Davies for many discussions and valuable comments on earlier versions of this paper. D. Bresch is thanked for providing the three-dimensional visualisation tool. A significant part of this study was performed while the author was at the ETHZ, Switzerland. Meteoswiss is thanked for providing access to ECMWF data.

Edited by: A. Stohl

\section{References}

Ancellet, G., Pelon, J., Beekmann, M., Papayannis, A., and Mégie, G.: Ground-based studies of ozone exchanges between the stratosphere and the troposphere, J. Geophys. Res., 96, 22 40122 421, 1991.

Andrews, D. G., Holton, J. R., and Leovy, C. B.: Middle Atmosphere Dynamics, Academic Press, San Diego, Calif., 1987.

Appenzeller, C., Davies, H. C., and Norton, W. A.: Fragmentation of stratospheric intrusions, J. Geophys. Res., 101, 1435-1456, $1996 a$.

Appenzeller, C., Holton, J. R., and Rosenlof, K. H.: Seasonal variation of mass transport across the tropopause, J. Geophys. Res., 101, $15071-15078,1996 b$. 
Bithell, M., Gray, L. J., and Cox, B. D.: A three-dimensional view of the evolution of midlatitude stratospheric intrusions, J. Atmos. Sci., 56, 673-688, 1999.

Bourqui, M.: Analysis and Quantification of STE: A Novel Approach, Ph.D. thesis, Swiss Federal Institute of Technology (ETH), 2001.

Bush, A. B. G. and Peltier, W. R.: Tropopause folds and synopticscale baroclinic wave life cycles, J. Atmos. Sci., 51, 1581-1604, 1994.

Collins, W. J., Derwent, R. G., Garnier, B., Johnson, C. E., Sanderson, M. G., and Stevenson, D. S.: Effect of stratospheretroposphere exchange on the future tropospheric ozone trend, J. Geophys. Res., 108, 8528, doi:10.1029/2002JD002617, 2003.

Cristofanelli, P., Bonasoni, P., Collins, W., Feichter, J., Forster, C., James, P., Kentarchos, A., Kubik, P. W., Land, C., Meloen, J., Roelofs, G. J., Siegmund, P., Sprenger, M., Schnabel, C., Stohl, A., Tobler, L., Tositti, L., Trickl, T., and Zanis, P.: Stratosphereto-troposphere transport: A model and method evaluation, J. Geophys. Res., 108, 8525, doi:10.1029/2002JD002600, 2003.

Danielsen, E. F.: Stratospheric source for unexpectedly large values of ozone measured over the pacific ocean during Gametag, August 1977, J. Geophys. Res., 85, 401-412, 1980.

Davies, H. C., Schär, C., and Wernli, H.: The palette of fronts and cyclones within a baroclinic wave development, J. Atmos. Sci., 48, 1666-1689, 1991.

Dessler, A. E. and Sherwood, S. C.: Effect of convection on the summertime extratropical lower stratosphere, J. Geophys. Res., 109, D23 301, doi:10.1029/2004JD005209, 2004.

Eisele, H., Scheel, H. E., Sladkovic, R., and Trickl, T.: Highresolution Lidar measurements of stratosphere-troposphere exchange, J. Atmos. Sci., 56, 319-330, 1999.

Gray, S. L.: A case study of stratosphere to troposphere transport: The role of convective transport and the sensitivity to model resolution, J. Geophys. Res., 108, 4590, doi:10.1029/2002JD003317, 2003.

Griffiths, M., Thorpe, A. J., and Browning, K. A.: Convective destabilization by a tropopause fold diagnosed using potentialvorticity inversion, Quart. J. Roy. Meteorol. Soc., 126, 125-144, 2000.

Hall, T. M. and Holzer, M.: Advective-diffusive mass flux and implications for stratosphere-tropopshere exchange, Geophys. Res. Lett., 30, 1222, doi:10.1029/2002GL016419, 2003.

Hartjenstein, G.: Diffusive decay of tropopause folds and the related cross-tropopause mass flux, Mon. Wea. Rev., 128, 2958-2966, 2000.

Haynes, P. H., Marks, C. J., McIntyre, M. E., Shepherd, T. G., and Shine, K. P.: On the 'downward control' of extratropical diabatic circulations by eddy-induced mean zonal forces, J. Atmos. Sci., 48, 651-678, 1991.

Holton, J. R., Haynes, P. H., McIntyre, M. E., Douglass, A. R., Rood, R. B., and Pfister, L.: Stratosphere-troposphere exchange, Rev. Geophys., 33, 403-439, 1995.

Hoskins, B. J.: Towards a PV- $\theta$ view of the general circulation, Tellus, 43, 27-35, 1991.

Hoskins, B. J., McIntyre, M. E., and Robertson, A. W.: On the use and significance of isentropic potential vorticity maps, Quart. J. Roy. Meteorol. Soc., 111, 877-946, 1985.

James, P., Stohl, A., Forster, C., Eckhardt, S., Seibert, P., and Frank, A.: A 15-year climatology of stratosphere-troposphere exchange with a Lagrangian particle dispersion model: 2. Mean climate and seasonal variability, J. Geophys. Res., 108, 8522, doi:10.1029/2002JD002639, 2003.

Juckes, M. N.: A generalisation of the transformed Eulerian-mean meridional circulation, Quart. J. Roy. Meteorol. Soc., 127, 147160, 2001.

Kowol-Santen, J., Elbern, H., and Ebel, A.: Estimation of crosstropopause airmass fluxes at midlatitudes: Comparison of different numerical methods and meteorological situations, Mon. Wea. Rev., 128, 4045-4057, 2000.

Ladstätter-Weissenmayer, A., Meyer-Arnek, J., Schlemm, A., and Burrows, J. P.: Influence of stratospheric airmasses on tropospheric vertical $\mathrm{O}_{3}$ columns based on GOME (Global Ozone Monitoring Experiment) measurements and backtrajectory calculation over the Pacific, Atmos. Chem. Phys., 4, 903-909, 2004, http://www.atmos-chem-phys.net/4/903/2004/.

Lamarque, J. F. and Hess, P. G.: Cross-tropopause mass exchange and potential vorticity budget in a simulated tropopause folding, J. Atmos. Sci., 51, 2246-2269, 1994.

Langford, A. O., Masters, C. D., Proffitt, M. H., Hsie, E.-Y., and Tuck, A. E.: Ozone measurements in a tropopause fold associated with a cut-off low system, Geophys. Res. Lett., 23, 25012504, 1996.

Majewski, D.: The Europa-Modell of the Deutscher Wetterdienst, Numerical Methods in Atmospherics Models, ECMWF, II, 147191, 1991.

McIntyre, M. E. and Palmer, T. N.: Breaking planetary waves in the stratosphere, Nature, 305, 593-600, 1983.

Meloen, J., Siegmund, P., van Velthoven, P., Kelder, H., Sprenger, M., Wernli, H., Kentarchos, A., Roelofs, G., Feichter, J., Land, C., Forster, C., James, P., Stohl, A., Collins, W., and Cristofanelli, P.: Stratosphere-troposphere exchange: A model and method intercomparison, J. Geophys. Res., 108, 8526, doi:10.1029/2002JD002274, 2003.

Mullendore, G. L., Durran, D. R., and Holton, J. R.: Crosstropopause tracer transport in midlatitude convection, J. Geophys. Res., 110, D06 113, doi:10.1029/2004JD005059, 2005.

Petterssen, S.: Motion and motion systems. Vol I, Weather analysis and forecasting, McGraw-Hill, 1956.

Poulida, O., Dickerson, R., and Heymsfield, A.: Stratospheretroposphere exchange in a mid-latitude mesoscale convective complex. 2. Numerical simulations, J. Geophys. Res., 101, 68236836, 1996.

Price, J. D. and Vaughan, G.: On the potential for stratospheretroposphere exchange in cut-off low systems, Quart. J. Roy. Meteorol. Soc., 119, 343-365, 1993.

Roelofs, G.-J. and Lelieveld, J.: Model study of the influence of cross-tropopause $\mathrm{O}_{3}$ transport on tropospheric $\mathrm{O}_{3}$ levels, Tellus, 49B, 38-55, 1997.

Roelofs, G. J., Kentarchos, A. S., Trickl, T., Stohl, A., Collins, W. J., Crowther, R. A., Hauglustaine, D., Klonecki, A., Law, K. S., Lawrence, M. G., von Kuhlmann, R., and van Weele, M.: Intercomparison of tropospheric ozone models: Ozone transport in a complex tropopause folding event, Tellus, 49B, 38-55, 1997.

Shapiro, M. A.: The role of turbulent heat flux in the generation of potential vorticity in the vicinity of upper-level jet stream systems, Mon. Wea. Rev., 104, 892-906, 1976.

Shapiro, M. A.: Turbulent mixing within tropopause folds as a mechanism for the exchange of chemical constituents between 
the stratosphere and troposphere, J. Atmos. Sci., 37, 994-1004, 1980.

Sprenger, M. and Wernli, H.: A northern hemispheric climatology of cross-tropopause exchange for the ERA-15 time period, J. Geophys. Res., 108, 8521, doi:10.1029/2002JD002636, 2003.

Stenchikov, G., Dickerson, R., Pickering, K., Ellis, W. J., Doddridge, B., Kondragunta, S., Poulida, O., Scala, J., and Tao, W. K.: Stratosphere-troposphere exchange in a mid-latitude mesoscale convective complex. 2. Numerical simulations, J. Geophys. Res., 101, 6837-6851, 1996.

Stohl, A.: A one-year Lagrangian "climatology" of airstreams in the northern hemisphere troposphere and lowermost stratosphere, J. Geophys. Res., 106, 7263-7279, 2001.

Stohl, A., Bonasoni, P., Cristofanelli, P., Collins, W., Feichter, J., Frank, A., Forster, C., Gerasopoulos, E., Gggeler, H., James, P., Kentarchos, T., Kromp-Kolb, H., Krüger, B., Land, C., Meloen, J., Papayannis, A., Priller, A., Seibert, P., Sprenger, M., Roelofs, G. J., Scheel, H. E., Schnabel, C., Siegmund, P., Tobler, L., Trickl, T., Wernli, H., Wirth, V., Zanis, P., and Zerefos, C.: Stratosphere-troposphere exchange: A review, and what we have learned from STOCCATO, J. Geophys. Res., 108, 8516, doi:10.1029/2002JD002490, 2003.

Sudo, K., Takahashi, M., and Akimoto, H.: Future changes in stratosphere-troposphere exchange and their impacts on future tropospheric ozone simulations, Geophys. Res. Lett., 30, 2256, doi:10.1029/2003GL018526, 2003.

Thorncroft, C. D., Hoskins, B. J., and McIntyre, M. E.: Two paradigms of baroclinic-wave life-cycle behaviour, Quart. J. Roy. Meteorol. Soc., 119, 17-56, 1993.
Wang, P. K.: Moisture plumes above thunderstorms anvils and their contributions to cross-tropopause transport of water vapor in midlatitudes, J. Geophys. Res., 108(D6), 4194, doi:10.1029/2002JD002581, 2003.

Wei, M.-Y.: A new formulation of the exchange of mass and trace constituents between the stratosphere and the troposphere, J. Atmos. Sci., 44, 3079-3086, 1987.

Wernli, H. and Bourqui, M.: A Lagrangian "1-year climatology" of (deep) cross-tropopause exchange in the extratropical Northern Hemisphere, J. Geophys. Res., 107(D2), 4021, doi:10.1029/2001JD000812, 2002.

Wernli, H. and Davies, H. C.: A Lagrangian-based analysis of extratropical cyclones. Part I: The method and some applications, Quart. J. Roy. Meteorol. Soc., 123, 467-489, 1997.

Wirth, V.: Diabatic heating in an axisymetric cut-off cyclone and related stratosphere-troposphere exchange, Quart. J. Roy. Meteorol. Soc., 121, 127-147, 1995a.

Wirth, V.: Comments on "A new formulation of the exchange of mass and trace constituents between the stratosphere and the troposphere", J. Atmos. Sci., 52, 2491-2493, 1995 b.

Wirth, V. and Egger, J.: Diagnosing extratropical synoptic-scale stratosphere-troposphere exchange: A case study, Quart. J. Roy. Meteorol. Soc., 125, 635-655, 1999.

Zierl, B. and Wirth, V.: The role of radiation for stratospheretroposphere exchange in an upper tropospheric anticyclone, J. Geophys. Res., 102, 23 883-23 894, 1997. 